\title{
A botulinum toxin-derived targeted secretion inhibitor downregulates the GH/IGF1 axis
}

\author{
Emmanuel Somm, ${ }^{1}$ Nicolas Bonnet, ${ }^{2}$ Alberto Martinez, ${ }^{3}$ Philip M.H. Marks, ${ }^{3}$ \\ Verity A. Cadd, ${ }^{3}$ Mark Elliott, ${ }^{3}$ Audrey Toulotte,, ${ }^{1}$ Serge L. Ferrari, ${ }^{2}$ René Rizzoli, ${ }^{2}$

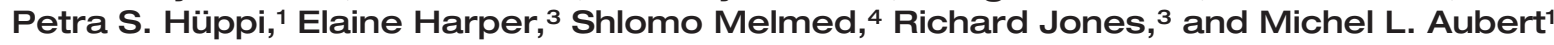 \\ 1Division of Development and Growth, Department of Paediatrics, and 2Division of Bone Diseases, Department of Rehabilitation and Geriatrics, \\ University of Geneva School of Medicine, Geneva, Switzerland. ${ }^{3}$ Syntaxin Ltd., Abingdon, Oxon, United Kingdom. \\ ${ }^{4}$ Pituitary Center, Department of Medicine, Cedars-Sinai Medical Center, Los Angeles, California, USA.
}

\begin{abstract}
Botulinum neurotoxins (BoNTs) are zinc endopeptidases that block release of the neurotransmitter acetylcholine in neuromuscular synapses through cleavage of soluble $\mathbf{N}$-ethylmaleimide-sensitive fusion (NSF) attachment protein receptor (SNARE) proteins, which promote fusion of synaptic vesicles to the plasma membrane. We designed and tested a BoNT-derived targeted secretion inhibitor (TSI) targeting pituitary somatotroph cells to suppress growth hormone (GH) secretion and treat acromegaly. This recombinant protein, called SXN101742, contains a modified GH-releasing hormone (GHRH) domain and the endopeptidase domain of botulinum toxin serotype $\mathrm{D}\left(\mathrm{GHRH}-\mathrm{LH}_{\mathrm{N}} / \mathrm{D}\right.$, where $\mathrm{H}_{\mathrm{N}} / \mathrm{D}$ indicates endopeptidase and translocation domain type $\left.\mathrm{D}\right)$. In vitro, SXN101742 targeted the GHRH receptor and depleted a SNARE protein involved in GH exocytosis, vesicle-associated membrane protein 2 (VAMP2). In vivo, administering SXN101742 to growing rats produced a dose-dependent inhibition of GH synthesis, storage, and secretion. Consequently, hepatic IGF1 production and resultant circulating IGF1 levels were reduced. Accordingly, body weight, body length, organ weight, and bone mass acquisition were all decreased, reflecting the biological impact of SXN101742 on the GH/IGF1 axis. An inactivating 2 -amino acid substitution within the zinc coordination site of the endopeptidase domain completely abolished SXN101742 inhibitory actions on GH and IGF1. Thus, genetically reengineered BoNTs can be targeted to nonneural cells to selectively inhibit hormone secretion, representing a new approach to treating hormonal excess.
\end{abstract}

\section{Introduction}

Botulinum neurotoxins (BoNTs) represent a family of 7 antigenically distinct molecules (identified by serotype) produced by strains of bacteria Clostridium botulinum. BoNTs produce botulism, which results from their capacity to block neuromuscular signal transmission (1). The mechanism of action of BoNTs occurs in distinct phases, including binding to cell receptors, cell internalization, endosomal escape, and finally, cleavage of soluble N-ethylmaleimide-sensitive fusion (NSF) attachment protein receptor (SNARE) proteins involved in fusion of exocytosis vesicles, which enable neurotransmitter release $(2,3)$. BoNTs share a similar structure consisting of a heavy chain (HC) of approximately $100 \mathrm{kDa}$ bound through a single disulfide bond to a light chain (LC) of approximately $50 \mathrm{kDa}$. The $\mathrm{HC}$ is itself composed of a C-terminal domain involved in target cell binding $\left(\mathrm{H}_{\mathrm{C}}\right)$ and an $\mathrm{N}$-terminal domain $\left(\mathrm{H}_{\mathrm{N}}\right)$ allowing target cell membrane translocation (4), whereas the LC, via its endopeptidase catalytic activity, cleaves SNARE proteins involved in vesicle/ membrane fusion $(2,3)$. Presently, BoNTs are clinically used to treat various pathologies involving specific muscular hypercontraction (such as strabismus, achalasia, and cervical dystonia) or autonomic nervous system dysfunction (for example, glandular hypersecretion causing hyperhidrosis or hypersalivation) (5). BoNTs are also widely used for cosmetic purposes, such as attenuation of facial wrinkles (6). To date, these diverse applications have all shared a neuronally based mechanism of action. The applicability of BoNTs' pharmacological

Conflict of interest: Alberto Martinez, Philip M.H. Marks, Verity A. Cadd, Mark Elliott, Elaine Harper, and Richard Jones are employees of Syntaxin Ltd. Shlomo Melmed and Michel L. Aubert are scientific consultants to Syntaxin Ltd.

Citation for this article: J Clin Invest. 2012;122(9):3295-3306. doi:10.1172/JCI63232. properties to nonneural cells, which enhances their therapeutic value (7), has been enabled by a new approach in which the original C-terminal domain of the $\mathrm{HC}$ is replaced by a ligand domain specific to a selected cell-type receptor, promising to deliver targeted secretion inhibitors (TSI). In this sense, the chemical conjugation of a BoNT derivative retaining catalytic activity with an alternative cell-binding ligand was previously shown to inhibit the secretory mechanisms in different cell types in vitro (8).

Pituitary growth hormone (GH) hypersecretion caused by an adenoma of somatotroph cells leads to acromegaly, a mature-onset endocrine pathology involving disproportionate skeletal and organ growth $(9,10)$. High GH and IGF1 plasma levels characterizing acromegaly induce a range of comorbidities, such as arthritis, prognathism, glucose intolerance, and in the absence of medical control, increased mortality due to cardiovascular, cerebrovascular, and pulmonary dysfunctions $(9,10)$. Classical treatment for acromegaly includes surgery, radiotherapy, and pharmacological therapies aimed either at suppressing the exacerbated GH secretion (including somatostatin receptor ligands or dopamine agonists) or blocking peripheral GH action with GH receptor antagonists (11). Normalizing GH and IGF1 status in acromegaly reverses the increased mortality (12), but surgery and currently available drugs only control disease activity in a subset of patients (13-15), underscoring the requirement for novel treatments. Accordingly, we propose an approach aimed at lowering GH secretion by directly inhibiting exocytosis of GHcontaining pituitary vesicles. To this end, we designed and produced a recombinant protein comprising a $\mathrm{GH}$-releasing hormone (GHRH) peptide ligand domain and the $\mathrm{LC}+\mathrm{H}_{\mathrm{N}}$ of the BoNT serotype $\mathrm{D}$ (GHRH-LH $\mathrm{H}_{\mathrm{N}} / \mathrm{D}$, where $\mathrm{H}_{\mathrm{N}} / \mathrm{D}$ indicates translocation domain type $\mathrm{D}$; named SXN101742). This BoNT-derived TSI is specifically designed 
A

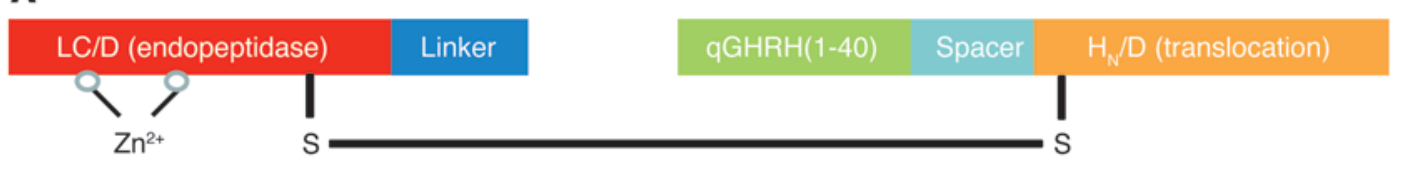

SXN101742

active

endopeptidase
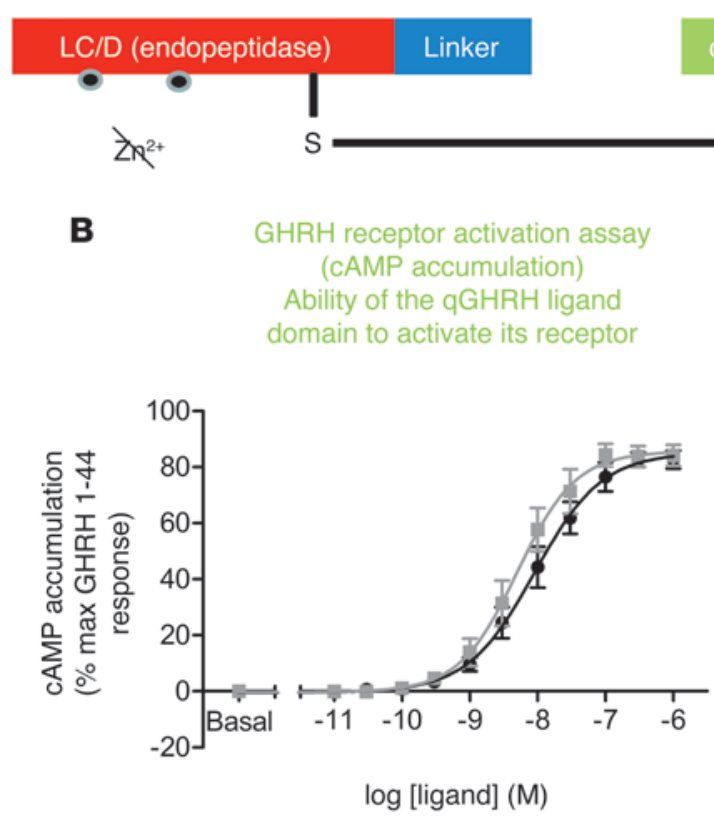

log [ligand] (M)
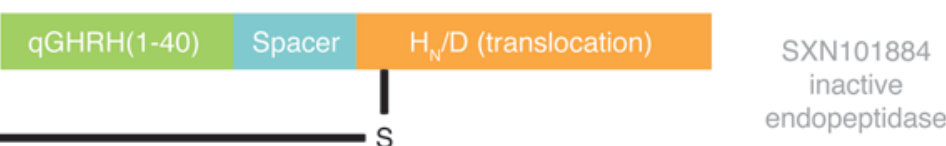

C

LC/D endopeptidase activity

(VAMP cleavage)

Ability of the LC/D domain to cleave its substrate
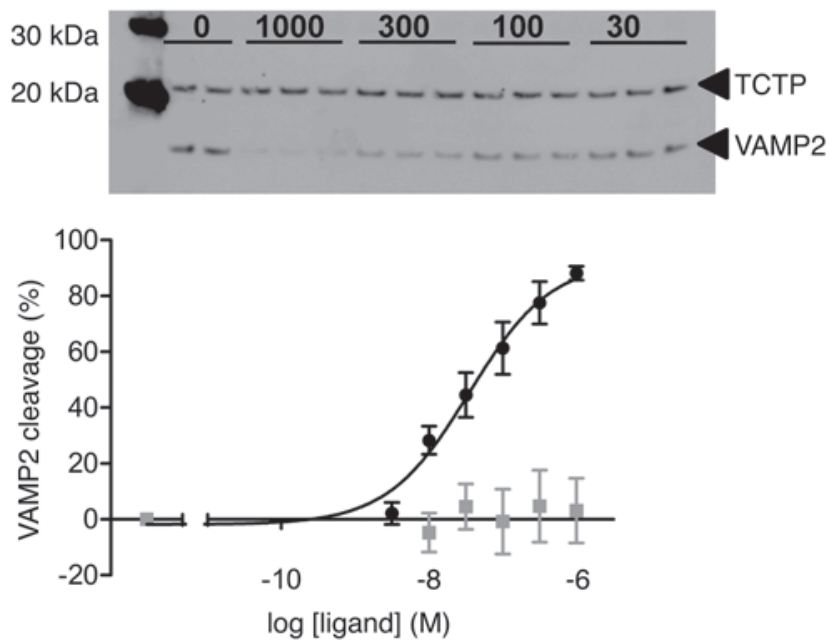

Figure 1

Structure of TSI SXN101742 and its inactivated form SXN101884 and functional testing of their targeting domain (qGHRH[1-40]) and their endopeptidase domain (LC/D) in GH3 cells expressing the rat GHRH receptor (GH3-rGHRH-R cells). (A) Schematic representation of SXN101742 (harboring an active endopeptidase domain) and SXN101884 (harboring an inactive endopeptidase domain). (B) Accumulation of cAMP, reflecting the activation of the rat GHRH receptor, in GH3-rGHRH-R cells incubated with SXN101742 (circles) or SXN101884 (squares). Results are expressed as mean \pm SEM. $n=4-5$ experiments performed in triplicate. (C) VAMP2 cleavage, reflecting the endopeptidase activity, assessed by Western blot, in GH3-rGHRH-R cells incubated with SXN101742 (black circles) or SXN101884 (gray squares) for 72 hours. Results are expressed as mean \pm SEM. $n=3$ independent experiments performed in triplicate. $\mathrm{Zn}$, zinc.

to exclusively bind GHRH receptors at the surface of somatotrophs and enter these cells, releasing the catalytic LC into the cytoplasm that cleaves vesicle-associated membrane proteins (VAMP), thereby blocking GH secretory granule exocytosis. In the absence of spontaneous animal models of pituitary GH hypersecretion and in order to demonstrate proof-of-concept of the potential therapeutic benefits of the GHRH-LHN/D protein, we tested this TSI both in vitro, in GH3 cells stably expressing the rat GHRH receptor, and in vivo, in juvenile rats, taking advantage of their rapid growth correlated with their endogenously high GH/IGF1 axis activity.

\section{Results}

In vitro studies with SXN101742 and SXN101884. SXN101742 is a multidomain multifunctional TSI. This recombinant protein was rationally engineered from Clostridium BoNT serotype D. SXN101742 comprises a GHRH receptor targeting domain (qGHRH1-40) as well as an LC endopeptidase type D domain (LC/D) (known to spe- cifically cleave VAMP in the target cell cytosol) and an HC translocation domain $\left(\mathrm{H}_{\mathrm{N}} / \mathrm{D}\right)$ (facilitating transport of the LC/D across the endosomal membrane into the cytosol) linked together by a disulfide bond (Figure 1A). A mutant form of this TSI in which the $\mathrm{LC} / \mathrm{D}$ is inactivated due to a 2 -amino acid substitution in the zinc-binding site (endonegative form named SXN101884) was also engineered (Figure 1A). SXN101742 and SXN101884 both elicited concentration-dependent increases in intracellular cAMP accumulation in GH3 cells stably expressing the rat GHRH receptor (GH3rGHRH-R cells) (Figure 1B and Table 1). There was no difference in the potency $\left(\mathrm{pEC}_{50}\right)$ or maximum response $\left(\mathrm{E}_{\max }\right)$ produced by the endopeptidase-positive (SXN101742) and endopeptidase-negative (SXN101884) proteins (Table 1), reflecting a similar potency for the GHRH receptor. In contrast, only increasing concentrations of SXN101742, but not SXN101884, produced a dose-dependent, and almost complete, depletion of VAMP2 in GH3-rGHRH-R cells (Figure 1C). Taken together, these in vitro results demonstrate that 


\section{Table 1}

Parameters obtained from SXN101742 and SXN101884 concentration effect curves in GH3-rGHRH-R cells

$\begin{array}{lccr}\text { Ligand/SXN protein } & \text { pEC }_{50} & \text { Emax (\% GHRH1-44 maximum) } & \text { Hill slope }\left(\boldsymbol{n}_{\mathrm{H}}\right) \\ \text { SXN101742 (batch no. 1) } & 8.05 \pm 0.17 & 85.5 \pm 2.7 & 0.94 \pm 0.02 \\ \text { SXN101742 (batch no. 2) } & 8.33 \pm 0.14 & 83.8 \pm 3.2 & 1.08 \pm 0.05 \\ \text { SXN101884 } & 8.29 \pm 0.16 & 85.8 \pm 3.6 & 1.16 \pm 0.10\end{array}$

Potency $\left(p E C_{50}=-\log E C_{50}\right)$, maximum effect $\left(E_{\max }\right)$, and Hill slope values were calculated from concentration effect curves shown in Figure 1B. $E_{\text {max }}$ is expressed as a percentage of the maximum value obtained with $\mathrm{GHRH} 1-44$. Results are expressed as mean \pm SEM. $n=4-5$ experiments performed in triplicate.

SXN101742 and SXN101884 similarly activate the G protein-coupled GHRH receptor targeted as an "entry door" for cellular internalization. However, only SXN101742 retaining the endopeptidase activity is able to cleave VAMP2 protein, which is involved in GH vesicle exocytosis leading to $\mathrm{GH}$ secretion.

In vivo effects of a single administration of SXN101742 on GH production and pituitary gland. Ten days after a single injection of SXN101742, circulating GH levels were strongly decreased in treated rats (Figure 2A). Pituitary glands of treated rats weighed less ( 25\%) than those of controls (Figure 2B), and histological evaluation showed hypotrophy mostly reflected by decreased size of the anterior lobe with unaltered posterior and intermediate lobes (Figure 2C). Pituitary Gh1 gene expression was strongly attenuated, by $70 \%$ in treated rats (Figure 2D), whereas gene expression of the other anterior pituitary hormones was unchanged. In contrast, prolactin gene expression was increased by $90 \%$ (Figure 2D). Most cells of the anterior pituitary represented somatotrophs (GH-positive cells), and in accordance with the attenuated circulating GH levels and gene expression, pituitary GH immunostaining appeared less intense in treated rats (Figure 2E).

Effects of SXN101742-induced GH inbibition on IGF1 levels and body growth. Hepatic Igf1 gene expression, known to be mainly driven by $\mathrm{GH}$, was markedly attenuated in treated rats (Figure 3A). Gene expression of acid-labile subunit (Igfals) and IGF-binding protein-3 (Igfbp3), 2 proteins forming a ternary complex with IGF1 and themselves also under direct $\mathrm{GH}$ control, were concomitantly decreased in treated rats (Figure 3A), providing further evidence of the effect of decreased GH secretion on GH-regulated genes. In contrast, hepatic Igf2 and Igfbp1 gene expression, known to be non-GH regulated, were both increased in treated rats (Figure $3 \mathrm{~A}$ ). Plasma IGF1 levels dropped rapidly, as first seen 3 days after SXN101742 administration, and thereafter remained approximately half of control values in animals treated with $1 \mathrm{mg} / \mathrm{kg}$ SXN101742 (Figure 3B). As GH and IGF1 are key stimulators of somatic growth, end points of this process were assessed. In contrast with control rats, which continuously gained weight, treated rats exhibited arrested weight gain a few days after SXN101742 administration (Figure 3C). This delay in growth arrest could represent a growth process not immediately responding to decreased GH and IGF1 or could also be explained by the early transient hyperphagia occurring after injection of SXN101742. Treated animals exhibited both a decrease $(-5 \%)$ in nose-to-anus length (Figure 3D) and attenuated organ growth, as demonstrated by reduced liver, heart, and kidney weights (Figure 3E).

Taken together, results of this single-dose injection show that SXN101742 strongly reduced pituitary GH synthesis and secretion. Secondarily, this marked GH decrease affected hepatic and circulating IGF1 levels, with resultant suppressed growth dynamics of these juvenile rats. These results prompted us to perform a dose-response study and to analyze cumulative effects on bone mass acquisition.

Dose-response effects of a single administration of SXN101742 on pituitary gland and body growth. To assess whether inhibition of the GH/ IGF1 axis was dose dependent, we treated juvenile growing rats with a single i.v. injection and examined them over a 10-day followup period using 3 doses of SXN101742 (0.1, 0.3, and $1.0 \mathrm{mg} / \mathrm{kg})$.

Pituitary weight (Figure 4A), GH content per pituitary (Figure 4B), and $\mathrm{GH}$ content normalized per pituitary protein content (Figure 4C), reflecting GH synthesis, were all dose dependently decreased in treated rats. Interestingly, individual values of plasma $\mathrm{GH}$, measured 3 days (Figure 4D), 6 days (Figure 4E), and 9 days (Figure 4F) after administration of SXN101742, showed that random GH peaks observed in control rats at each time point were reduced with the 0.1 and $0.3 \mathrm{mg} / \mathrm{kg}$ doses and were totally abolished with the highest $(1 \mathrm{mg} / \mathrm{kg})$ dose. The inhibitory effect of SXN101742 on GH production was specific, since thyroid-stimulating hormone (TSH) content per pituitary (Figure 4G), TSH content normalized per pituitary protein content (Figure $4 \mathrm{H}$ ), and prolactin hormone (PRL) content per pituitary (Figure $4 \mathrm{I}$ ) were unchanged in treated rats. PRL content normalized per pituitary protein content (Figure $4 \mathrm{~J}$ ) was increased by $38 \%$ in rats treated with 0.3 and $1 \mathrm{mg} / \mathrm{kg}$ of SXN101742, in accordance with observed enhanced Prl gene expression depicted in Figure 2D. Circulating levels of PRL were, however, undetectable, both in control and SXN101742-treated rats (data not shown).

Hepatic Igf1 gene expression (Figure 5A) and protein content (Figure 5B) were significantly decreased in the rats treated with $1 \mathrm{mg} / \mathrm{kg}$ of SXN101742. Circulating IGF1 levels (Figure 5C) were dose dependently reduced and rats treated with $0.3 \mathrm{mg} / \mathrm{kg}$ exhibited delayed arrest in BW gain similar to that of those treated with $1 \mathrm{mg} / \mathrm{kg}$ when compared with controls (Figure 5D). Rats treated with the lowest dose $(0.1 \mathrm{mg} / \mathrm{kg})$ showed an earlier attenuation of BW gain (Figure 5D), possibly due to the absence of transient hyperphagia observed for this group (Figure 5E). At sacrifice, all treated animals exhibited decreased nose-to-anus length (Figure 5F).

Dose-response effects of a single administration of SXN101742 on bone mass acquisition. To further validate the biological impact of SXN101742induced inhibition of the GH/IGF1 axis (considered as the main hormonal regulator of bone mass development; refs. 16-24), we performed micro-CT and histological bone analyses of treated and control rats. At the structural level, femoral length (Figure 6A), cross-sectional area (Figure 6B), and trabecular number (Figure 6C) were all reduced with the administered doses of SXN101742. Representative 3D image reconstruction of distal trabecular structure, longitudinal sections, and transversal sections (Figure 6D) illustrate these changes. Concordant with reduced bone length, thickness of the growth plate was decreased with the 0.3 and $1 \mathrm{mg} / \mathrm{kg}$ doses (Figure 6E). Representative growth plate images (Figure 6F) clearly indicate that 

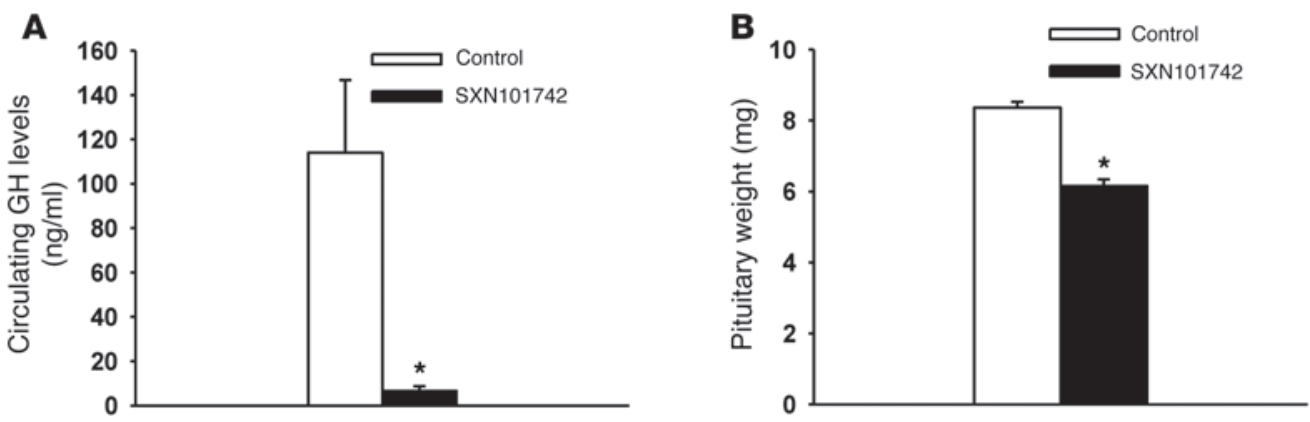

C

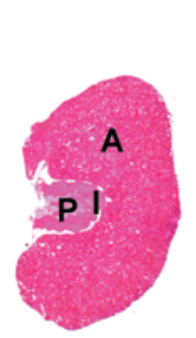

Control
D

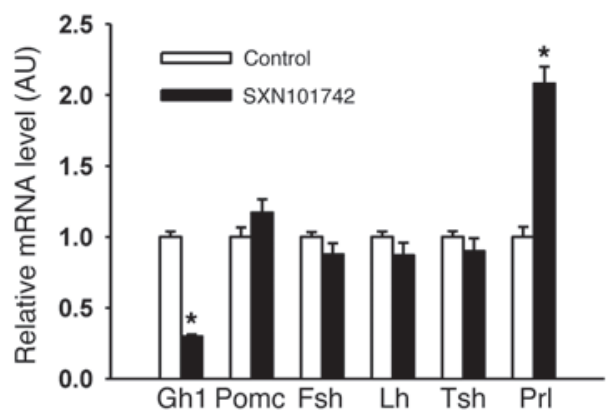

E

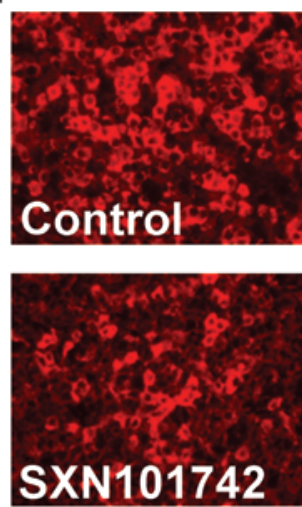

\section{Figure 2}

SXN101742 decreases GH plasma levels and inhibits pituitary GH production in juvenile rats (experiment no. 1). (A) Plasma GH levels (ng/ml). ${ }^{*} P<0.005$. (B) Total weight of pituitary glands (mg). ${ }^{*} P<0.001$. (C) Staining of pituitary sections (H\&E). Note the hypoplasia of the anterior lobe (A) in SXN101742-treated rats with no change in intermediate lobe (I) and posterior lobe (P). (D) Relative gene expression for anterior pituitary hormones. ${ }^{*} P<0.001$. (E) GH immunostaining of anterior pituitary sections. Original magnification, $\times 40$. For all panels, 45 -day-old male rats received either a single i.v. injection of SXN101742 at the dose of $1 \mathrm{mg} / \mathrm{kg}$ (black columns) or vehicle (white columns) and were studied 10 days later. Results are expressed as mean \pm SEM. $n=12$ animals per group (A, B, and $\mathbf{D})$.

reduced thickness was likely due to a narrower proliferative cell layer, with no observed change in the differentiating cell layer. Moreover, at the cortical level, dynamic calcein staining indicated decreased mineral apposition rate (MAR) in all groups of treated animals (Figure 6G). The inhibitory effect on radial growth appeared specific for periosteal surfaces, with no change in endocortical compartments (Figure $6 \mathrm{H}$ ). These results confirm that inhibition of the $\mathrm{GH} /$ IGF1 axis attained with a single injection of SXN101742 is biologically relevant, since strong inhibitory effects were seen on both appositional and endochondral bone growth.

Lack of effect of SXN101884. In vitro, SXN101742 and SXN101884 were equipotent in terms of their GHRH receptor-activating activity (Figure 1B), but only SXN101742 elicited VAMP2 cleavage (Figure 1C), since the mutant version SXN101884 contains an inactivating 2 -amino acid substitution within the zinc coordination site of the $\mathrm{LH}_{\mathrm{N}} / \mathrm{D}$ domain. To demonstrate that the inhibitory effect of SXN101742 on GH secretion is dependent on endopeptidase activity, SXN101742 and SXN101884 were tested in parallel in growing rats.

Administration of a single dose ( $1 \mathrm{mg} / \mathrm{kg}$, i.v.) of this "endonegative" TSI (SXN101884) did not elicit any of the inhibitory effects seen with SXN101742 on pituitary weight (Figure 7A), GH content (Figure 7B), circulating GH peaks (Figure 7C) or IGF1 levels (Figure 7D), BW gain (Figure 7E), body length (Figure 7F), organ weight (Figure 7G), femur length (Figure 7H), and femur cross-sec- tional area (Figure 7I). Taken together, these results demonstrate that the endopeptidase activity of the $\mathrm{LH}_{\mathrm{N}} / \mathrm{D}$ domain is likely responsible for observed inhibitory actions of SXN101742 on GH secretion and the resultant peripheral effects.

\section{Discussion}

Since vesicle fusion with the plasma membrane involving the SNARE complex represents a universal mechanism for exocytosis in eukaryotic cells (25), the correction of pathologic protein secretion by engineering of BoNT-derived TSI appears to be a promising therapeutic tool. In fact, substitution of the HC domain of BoNTs with a chosen ligand domain results in a protein retargeted to cell types of interest expressing the corresponding receptor (26). After cell binding and internalization, the $\mathrm{H}_{\mathrm{N}}$ domain of the TSI enables translocation of a selected LC to the cytosol to specifically cleave a member of the SNARE protein family and ultimately durably inhibit secretion (26). Some in vitro reports have validated this strategy in PC12 cells (27), in HIT-T15 B cells (8), and in embryonic dorsal root ganglion neurons (28).

Management of patients with acromegaly presently includes different treatment modes aimed at reducing elevated GH levels and associated increased morbidity. Pituitary adenomas can be removed surgically (transsphenoidal resection), irradiated (radiotherapy), or pharmacologically treated with a somatostatin receptor ligand or a dopamine agonist to reduce elevated GH secretion 

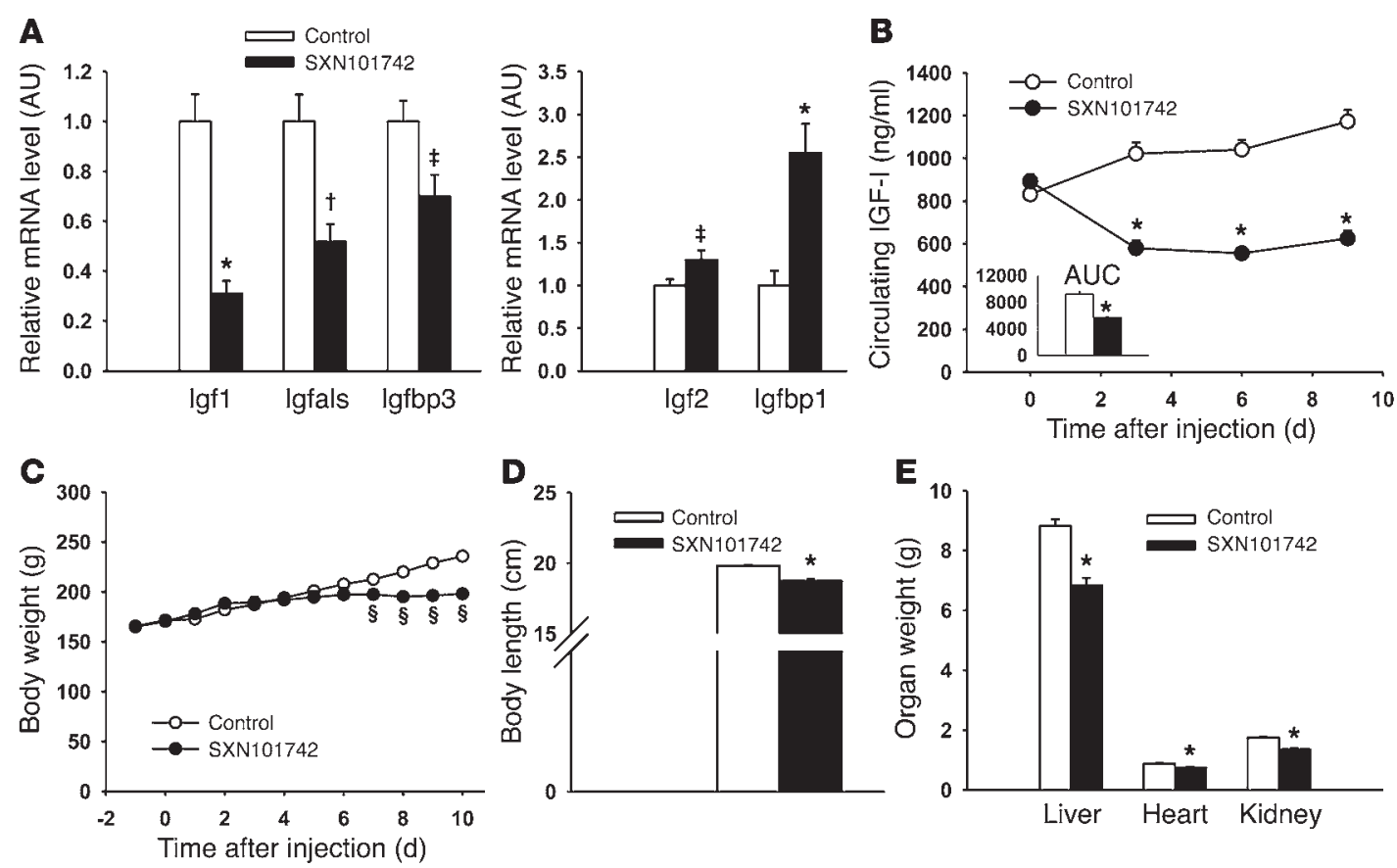

Figure 3

SXN101742-induced GH inhibition decreases IGF1 levels and inhibits somatic growth in juvenile rats (experiment no. 1). (A) Relative gene expression for lgf1, Igfals, Igfbp3, Igf2, and Igfbp1 in liver.(B) Time course of plasma IGF1 levels (ng/ml). (C) BW curves (g). (D) Body length (cm). (E) Weight of organs (liver, heart, kidney) (g). For all panels, 45-day-old male rats received either a single i.v. injection of SXN101742 at the dose of $1 \mathrm{mg} / \mathrm{kg}$ (black) or vehicle (white) and were studied over a 10-day period. Results are expressed as mean \pm SEM, $n=12$ animals per group. ${ }^{*} P<0.001 ;{ }^{\dagger} P<0.002 ;{ }^{\ddagger} P<0.05 ; § P<0.02$.

(9). However, a large proportion of somatotroph adenomas are not effectively treated, given that GH and IGF1 levels remain uncontrolled in a subset of patients (13-15).

Pituitary somatotroph cells express surface receptors for GHRH, somatropin release-inhibiting factor (SRIF), and Ghrelin (10). In fact, pituitary GH secretion is under stimulatory control by hypothalamic GHRH and ghrelin and under inhibitory control by hypothalamic SRIF $(29,30)$. We tested an approach to decreasing GH excess by directly manipulating the exocytosis process of pituitary GH-containing vesicles. Accordingly, we generated a novel TSI (SXN101742) comprising the association of a GHRH ligand domain-conferring specificity of somatotroph cell internalization through GHRH receptor binding (31) and the LC from BoNT serotype D, bearing VAMPcleaving activity (32). This therapeutic approach is further validated by observations that $\mathrm{GH}$-secreting pituitary tumors express GHRH receptors $(10,33)$ and would therefore be responsive to this GHRH receptor TSI. Previous work also reported a key role for VAMP proteins in the GH secretory process of rat anterior pituitary cells (34).

We demonstrated in vitro that SXN101742 activated cells expressing the GHRH receptor, reflecting GHRH-binding properties, and ultimately dose dependently cleaved cytoplasmic VAMP2. Interestingly, acute VAMP cleavage action should be amplified by the fact that this SNARE protein is normally recycled after vesicle fusion with the plasma membrane $(35,36)$.

Current rodent models of acromegaly do not truly recapitulate the human disease. Neither transgenic mice overexpressing GH ectopically $(37,38)$ nor rat models implanted with GH3 cell tumors (39) (not expressing the targeted GHRH receptor) are treatable by SXN101742. Therefore, we reasoned that in vivo proof of effi- cacy could be achieved by studying rat growth, a biological process involving high GH/IGF1 activity, as previously used for validation of somatostatin peptidomimetics (40). The paradigm chosen was to administer a single bolus of SXN101742 to 45-day-old male rats and to examine resulting effects on growth potential during the ensuing 10 days. In treated animals, in the absence of visible adverse effects, marked inhibition of GH secretion was observed, characterized by rapid abrogation of the usual GH secretory peaks. Surprisingly, both pituitary GH content and gene expression remained markedly decreased 10 days after a single SXN101742 injection, clearly indicating that GH synthesis was also attenuated. This reduced GH production and storage, unrelated to excessive secretion, was accompanied by observed hypotrophy of the anterior pituitary. In fact, somatotroph cells account for the most abundant pituitary gland mass, which is usually hypoplastic in animal models or patients exhibiting isolated GH deficiency $(41,42)$. Since SXN101742 action primarily involves blockade of the exocytic machinery, VAMP cleavage in this case, inhibition of GH synthesis may reflect the existence of an intracellular feedback mechanism in somatotroph cells, linking the failure of GH-containing vesicles to fuse with the plasma membrane to the repression of de novo GH synthesis. Blockade of GH secretion from somatotrophs could also abolish short GH feedback loops known to control GHRH and SRIF hypothalamic production (43-45), themselves regulating $\mathrm{GH}$ synthesis. In any case, this indirect inhibitory action of SXN101742 on GH synthesis could reinforce its therapeutic value compared with current acromegaly treatments.

Specificity of SXN101742 activity was demonstrated by the fact that gene expression and/or protein content for other anterior pituitary hormones (follicle-stimulating hormone [FSH], 


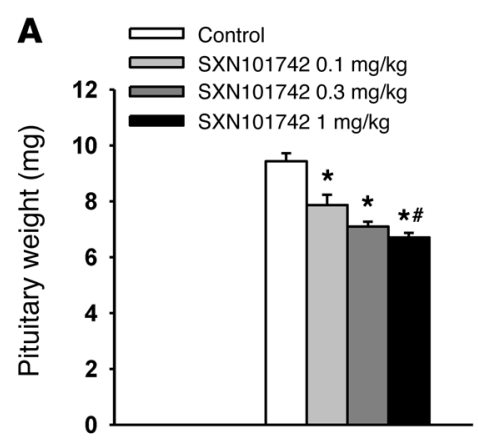

B
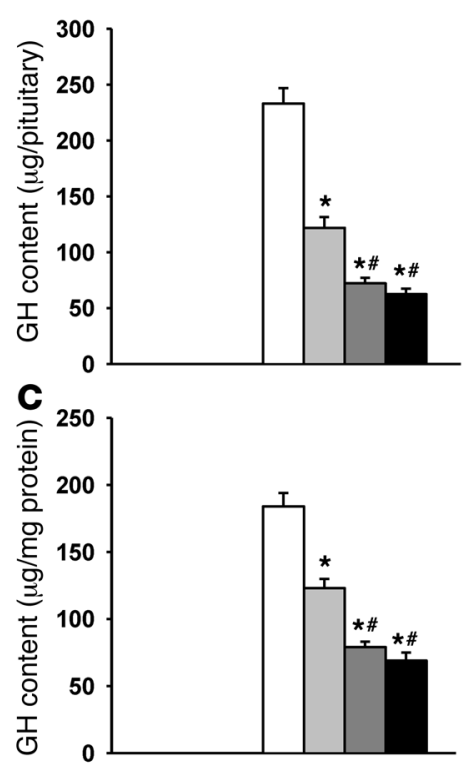

D

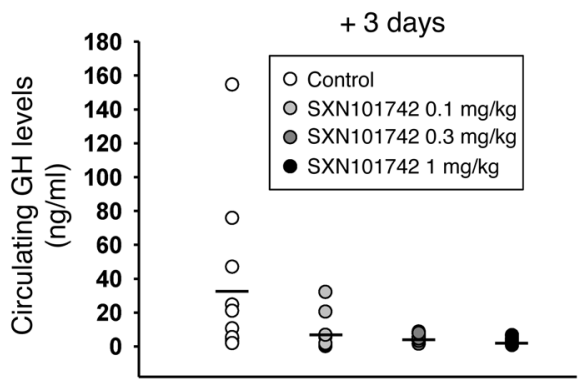

E

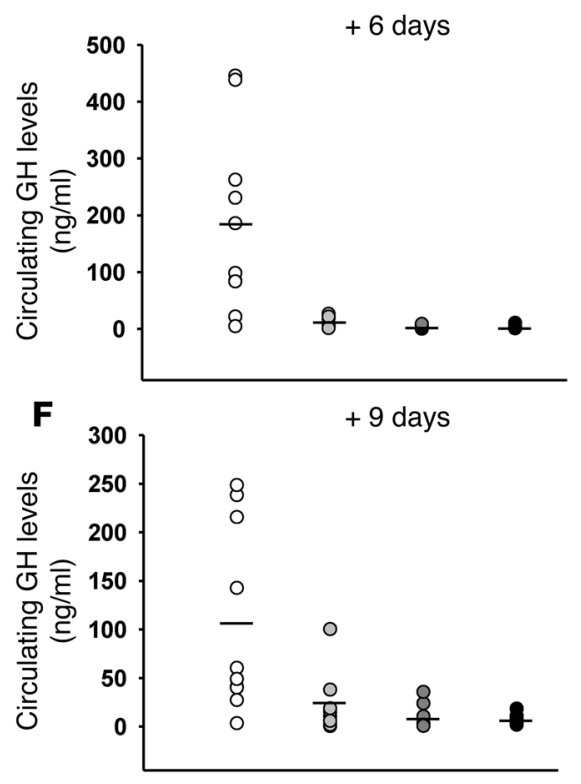

G
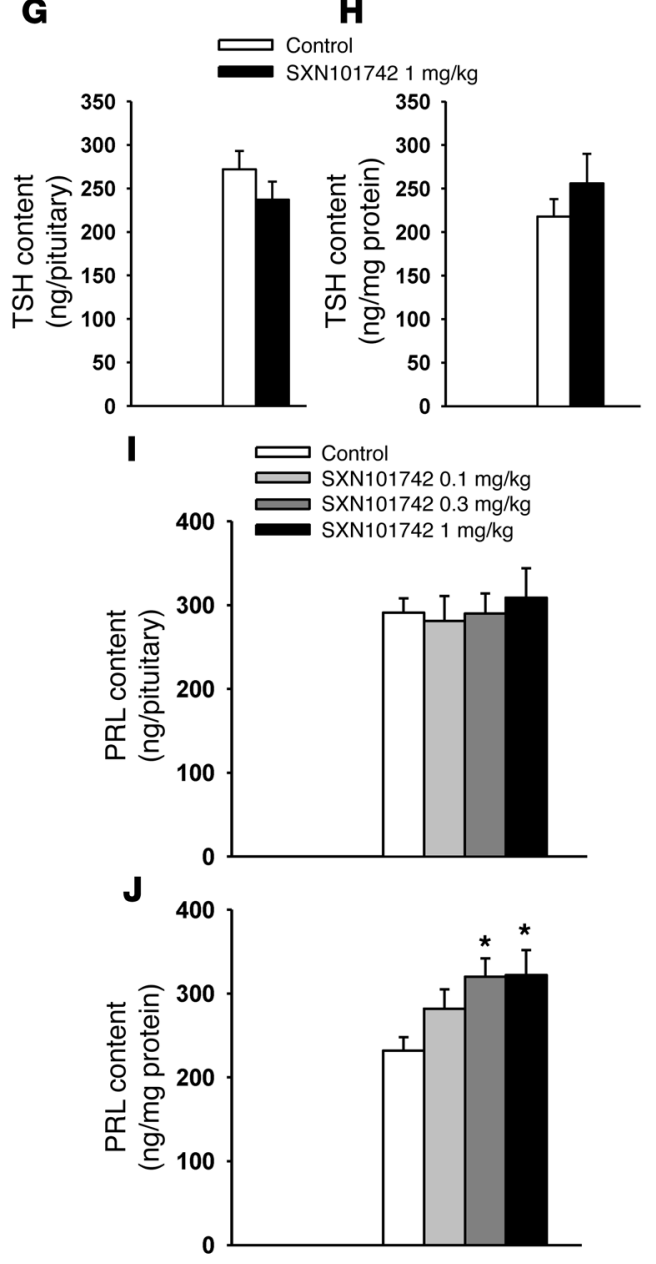

Figure 4

SXN101742 dose dependently decreases GH production and secretion in juvenile rats (experiment no. 2). (A) Total weight of pituitary glands (mg). ${ }^{*} P<0.005$ versus control group; ${ }^{\#} P<0.01$ versus $0.1 \mathrm{mg} / \mathrm{kg}$ group. (B) GH content of pituitary glands ( $\left.\mu \mathrm{g} / \mathrm{pituitary}\right) .{ }^{*} P<0.001$ versus control group; ${ }^{*} P<0.001$ versus $0.1 \mathrm{mg} / \mathrm{kg}$ group. (C) GH content of pituitary glands ( $\mu \mathrm{g} / \mathrm{mg}$ protein). ${ }^{*} P<0.001$ versus control group; ${ }^{*} P<0.001$ versus $0.1 \mathrm{mg} / \mathrm{kg}$ group. Results are expressed as mean \pm SEM and $n=8-12$ animals per group for $\mathbf{A}-\mathbf{C}$. (D-F) Plasma GH individual values $(\mathrm{ng} / \mathrm{ml})$. Blood samples were collected 3 days (D), 6 days $(\mathbf{E})$, and 9 days (F) after a single injection of SXN101742 at the dose of either 0.1 (light gray circles), 0.3 (dark gray circles), or $1 \mathrm{mg} / \mathrm{kg}$ (black circles) or vehicle (white circles). Bars represent the means of the corresponding groups. $n=8-10$ animals per group. (G) TSH content of pituitary glands (ng/pituitary). (H) TSH content of pituitary glands (ng/mg protein). (I) PRL content of pituitary glands (ng/pituitary). (J) PRL content of pituitary glands (ng/mg protein). ${ }^{*} P<0.02$ versus control group. Results are expressed as mean \pm SEM. $n=8-12$ animals per group for $\mathbf{G}-\mathbf{J}$.

luteinizing hormone [LH], ACTH, and TSH) remained unaltered after treatment, confirming that SXN101742 only bound to and entered somatotrophs and not other cell populations. In our experiments, low GH synthesis and secretion levels were associated with secondary prolactin synthesis increase, in accordance with the mildly elevated prolactin levels observed in dwarf $d w / d w$ rats $(46,47)$ or the hyperprolactinemia due to the lack of $\mathrm{GH}$ signaling (48). Several mechanisms could explain elevated prolactin synthesis, such as redirection of production in bihormonal somatolactotroph cells or altered dopaminergic tone inhibiting prolactin production. Increased prolactin mRNA and protein levels in treated rat pituitaries were, however, not associated with detectable elevated circulating levels in our rats, possibly reflecting the young age and male sex of the animals utilized in these experiments.
The use of SXN101884, an endopeptidase inactive TSI, clearly demonstrated that the inhibitory effect of SXN101742 on GH secretion is truly due to its endopeptidase activity. In fact, SXN101742 and SXN101884 are identical except for 2 amino acid substitutions within the catalytic site of the LC in SXN101884, which prevents efficient zinc ion coordination required for endopeptidase activity. Since stoichiometry and GHRH-binding domains are identical between the 2 molecules, SXN101884 could bind to and activate somatotroph cell GHRH receptors to the same extent as SXN101742, as confirmed in vitro by similar potency to induce cAMP accumulation in GH3-rGHRH-R cells. The in vivo data demonstrate that at the same dose, SXN101884 did not affect GH/IGF1 parameters studied.

Most pathophysiological features of GH overproduction, as seen in acromegaly, are mediated by excessive IGF1 production, which should be normalized in any effective therapeutic approach 
A

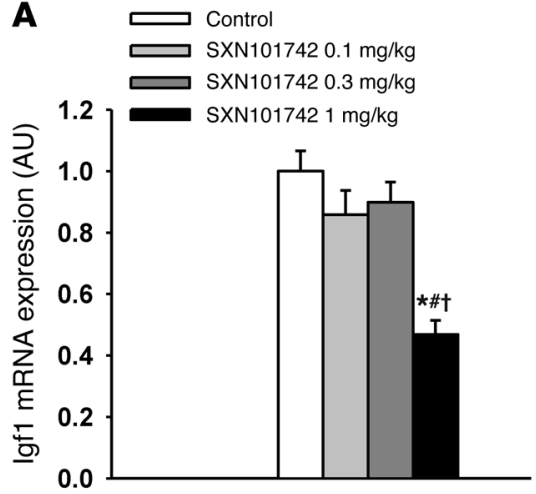

D

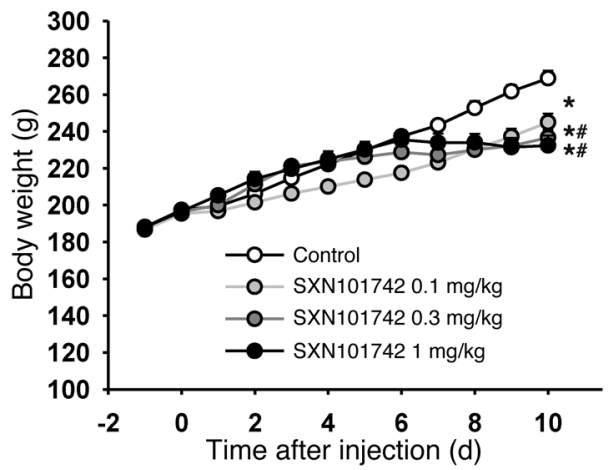

B

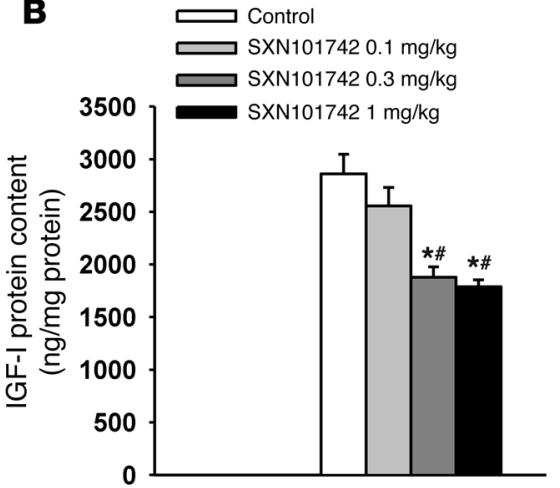

E

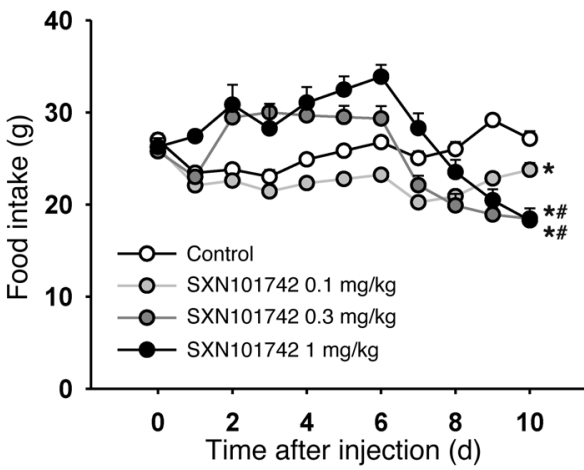

c

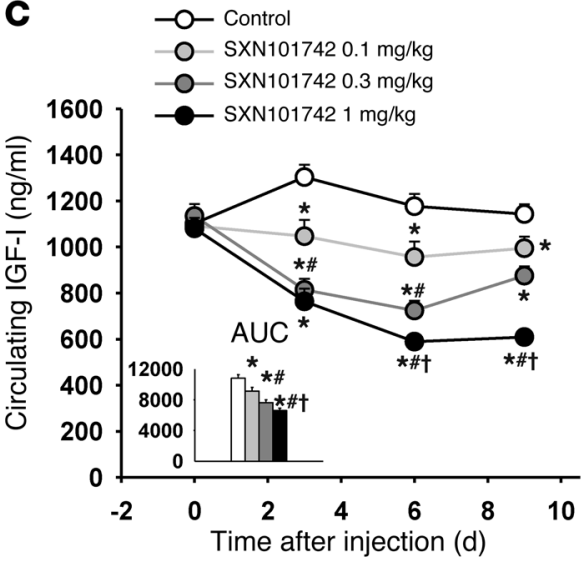

$\mathbf{F}$
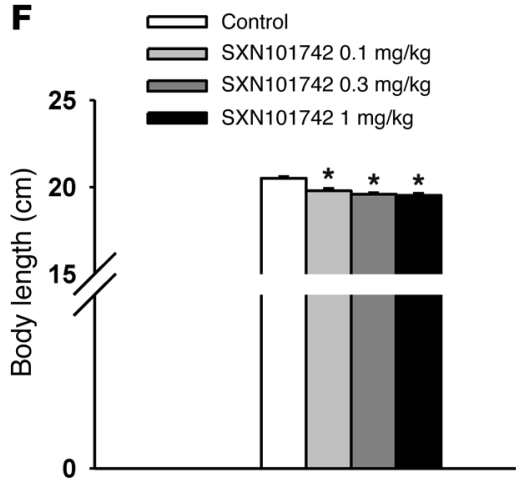

Figure 5

SXN101742-induced GH inhibition dose dependently decreases IGF1 levels and inhibits somatic growth in juvenile rats (experiment no. 2). (A) Relative gene expression for lgf1 in liver. ${ }^{*} P<0.001$ versus control group; $\# P<0.001$ versus $0.1 \mathrm{mg} / \mathrm{kg}$ group; ${ }^{\dagger} P<0.001$ versus $0.3 \mathrm{mg} / \mathrm{kg}$ group. (B) IGF1 protein content in liver (ng/mg protein). ${ }^{*} P<0.001$ versus control group; ${ }^{*} P<0.01$ versus $0.1 \mathrm{mg} / \mathrm{kg}$ group. (C) Time course of plasma IGF1 levels (ng/ml). * $P<0.05$ versus control group; ${ }^{\sharp} P<0.05$ versus $0.1 \mathrm{mg} / \mathrm{kg}$ group; ${ }^{\dagger} P<0.05$ versus $0.3 \mathrm{mg} / \mathrm{kg}$ group. Inset panel represents AUC, same significance as in the main panel. (D) BW curves (g). ${ }^{*} P<0.05$ versus control group; ${ }^{*} P<0.05$ versus $0.1 \mathrm{mg} / \mathrm{kg}$ group. (E) Food intake $(\mathrm{g}) .{ }^{*} P<0.05$ versus control group; ${ }^{\#} P<0.05$ versus $0.1 \mathrm{mg} / \mathrm{kg}$ group. $(\mathrm{F})$ Body length $(\mathrm{cm}) .{ }^{*} P<0.001$ versus control group. For all panels, 45-day-old male rats received either a single i.v. injection of SXN101742 at the dose of $0.1,0.3$, or $1 \mathrm{mg} / \mathrm{kg}$ or vehicle and were studied over a 10-day period. Results are expressed as mean \pm SEM. $n=8-10$ animals per group.

$(49,50)$. As expected, the marked reduction in GH output in SXN101742-treated rats resulted in significant depletion of hepatic IGF1 content, which correlated with a dose-dependent decrease in circulating IGF1 levels, in keeping with the known primary hepatic origin of circulating IGF1 (51). Blockade of GH signaling reduces IGF1 by different degrees in mouse models (52). In our high dosetreated rats in the mid-growth phase, abrogation of GH secretory peaks was associated with $50 \%$ reduction in IGF1 levels, suggesting that limited GH basal secretion and/or other regulators can yet maintain $50 \%$ of IGF1 secretion in the ad libitum-fed state. Clearly, if a similar scenario could be extrapolated to acromegaly patients, a $50 \%$ decrease in IGF1 secretion should be therapeutically valuable since, for comparison, a GH receptor antagonist treatment lowering IGF1 from baseline by $26 \%$ to $62 \%$ exhibits beneficial clinical effects (53). Liver gene expression of Igf2, a non-GH-regulated gene, was slightly increased in treated rats, excluding a direct hepatic effect of the TSI, independent of those arising secondarily from $\mathrm{GH}$ secretion. This observation could likely reflect a counterregulatory mechanism of IGF1 dampening. Clinically, a complete IGF1 gene deletion induces a moderate increase in serum IGF2 (54).
We also observed that the inhibition extent of both GH and IGF1 secretion is biologically relevant, since an arrest in BW gain was observed in treated rats. In contrast with the immediate inhibitory effect in BW gain observed with some somatostatin peptidomimetics (40), early GH and IGF1 inhibition in our treated rats showed a latency period before arrested weight gain was observed. This delay in growth arrest could be attributed to early transient hyperphagia occurring after administration of SXN101742, which remains to be explained. GHRH administration is known to produce an orexigenic action in rats (55). However, transiently increased food intake following SXN101742 administration does not appear to be related to GHRH receptor-binding activity of this molecule, since administration of SXN101884, equipotent in terms of GHRH receptor-activating activity, did not induce such an orexigenic effect. Further studies are needed to investigate whether the rapid variation in circulating GH could represent a nutritional stress signal inducing counterregulatory hyperphagia. Therefore, these experimental conditions could be insightful for study of crosstalk between GH levels and peripheral (such as ghrelin or leptin secretion) or cen- 
A

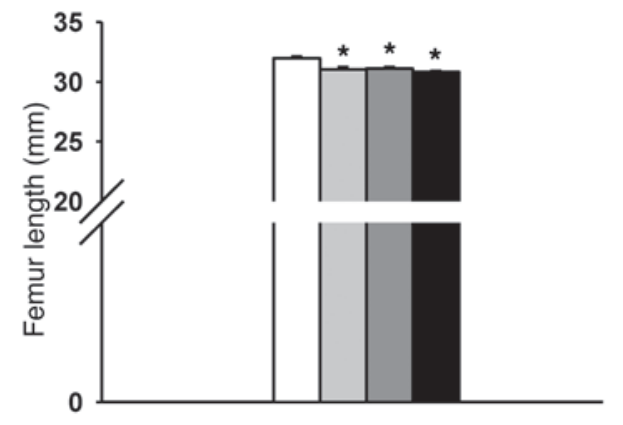

D

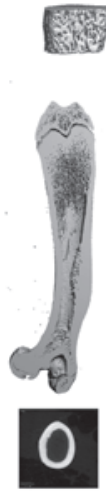

은

\section{W}

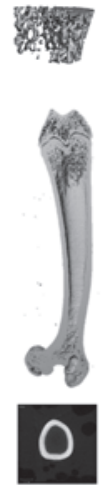

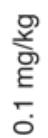

B

E

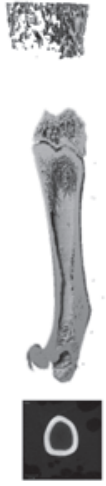

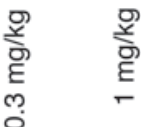

G

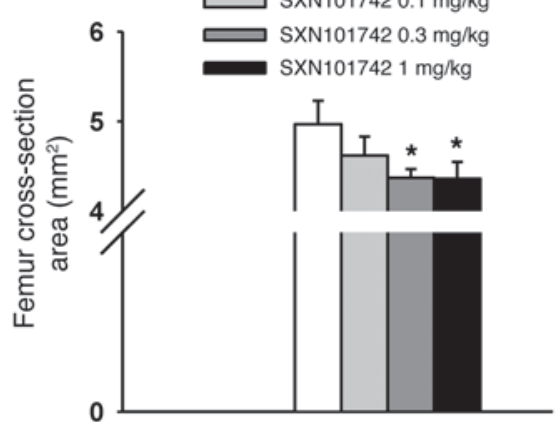

C

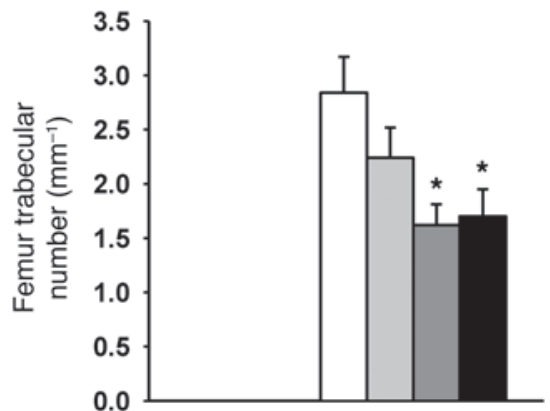

$\mathbf{F}$
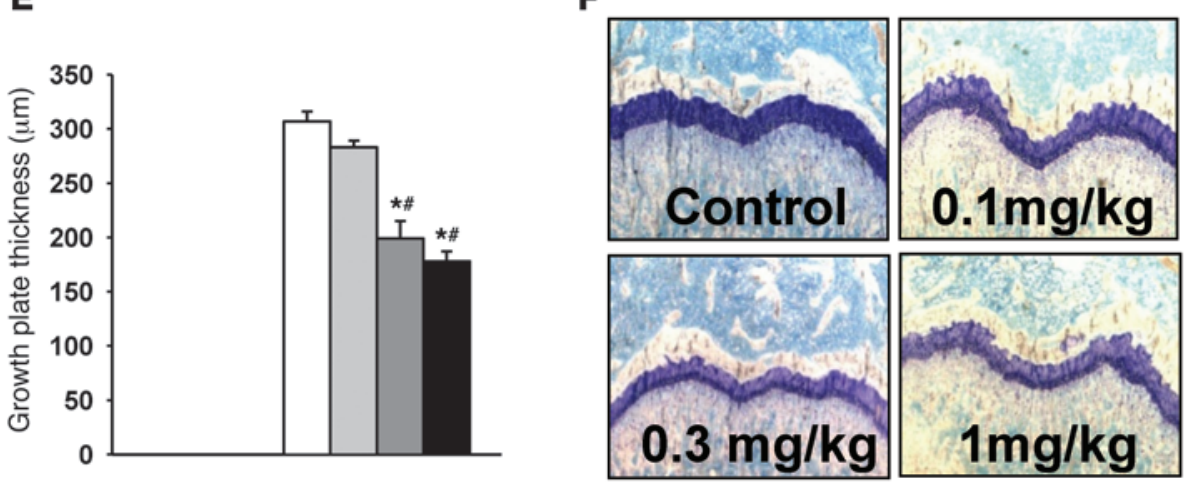

H

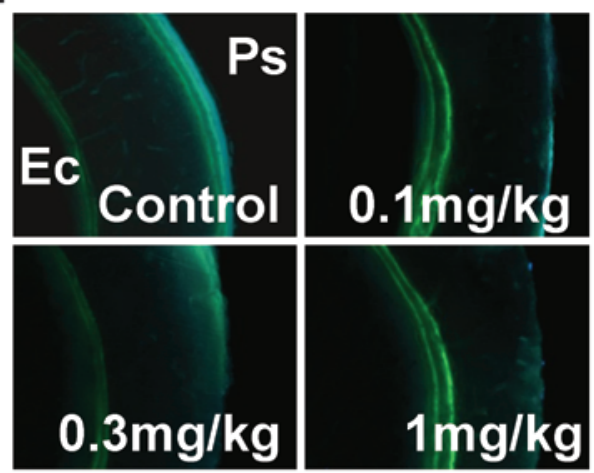

Figure 6

SXN101742 dose dependently inhibits bone mass acquisition in juvenile rats (experiment no. 2). (A) Femur length (mm). ${ }^{*} P<0.001$ versus control group. (B) Femur cross-section area $\left(\mathrm{mm}^{2}\right)$. ${ }^{\star} P<0.05$ versus control group. (C) Femur trabecular number $\left(\mathrm{mm}^{-1}\right)$. ${ }^{*} P<0.01$ versus control group. $n=6$ animals per group for A-C. (D) Images of tridimensional reconstruction of distal trabecular structure (top panel), longitudinal sections (middle panel), and transversal sections (bottom panel) of femurs. (E) Growth plate thickness $(\mu \mathrm{m})$. ${ }^{*} P<0.001$ versus control group; ${ }^{\sharp} P<0.01$ versus $0.1 \mathrm{mg} / \mathrm{kg}$ group. $n=5$ animals per group. (F) Growth plate histology (toluidine blue staining). Note the shortening of the proliferative cell layer without any change in the differentiating cell layer. (G) MAR $(\mu \mathrm{m} / \mathrm{d}),{ }^{*} P<0.002$ versus control group. $n=5$ animals per group. (H) Radial growth histology (calcein double-labeling method). Note the inhibitory effect of SXN101742 on the periosteal surface (PS) development with no change in the endocortical compartment (Ec). Results are expressed as mean \pm SEM. Original magnification, $\times 20(\mathbf{F}) ; \times 10(\mathbf{H})$.

tral signals (such as hypothalamic neuropeptide Y [NPY] level) regulating somatic growth as a function of energy status.

Growth deficit was also reflected by limited length increment and reduced organ weights. In fact, we observed that nose-to-anus length and both the absolute and relative (allometric) mass of liver, kidney, and heart were decreased in response to SXN101742 administration. Concomitant inhibition of both GH and IGF1 secretion in our model did not allow determination of their respective contributions to organ growth, as offered by genetically modified mice or hypophysectomized/supplemented rats, which indicate that liver size is main- ly determined by GH action $(56,57)$, whereas kidney size is more sensitive to IGF1 (58). Our results also confirm that bone development, and especially clonal expansion in individual growth plate chondrocyte columns, is highly sensitive to GH and IGF1 levels, as previously reported $(16,19,23,24)$. Low doses of SXN101742 produced a smaller reduction in circulating IGF1 levels than higher doses, but achieved almost the same level of bone mass deficiency, supporting the importance of direct $\mathrm{GH}$ action on bone development and longitudinal growth (59). In high-dose-treated rats, abolition of pulsatile GH secretion, followed by a 50\% reduction in circulating IGF1 levels, 
A
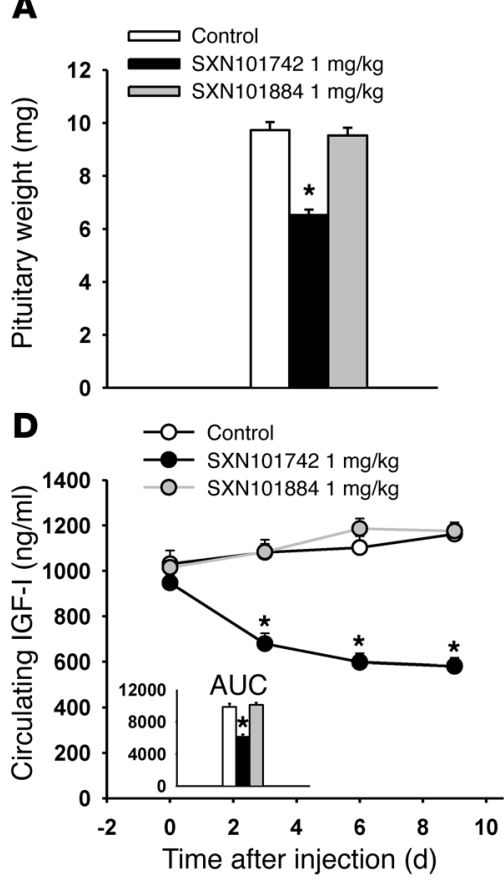

G

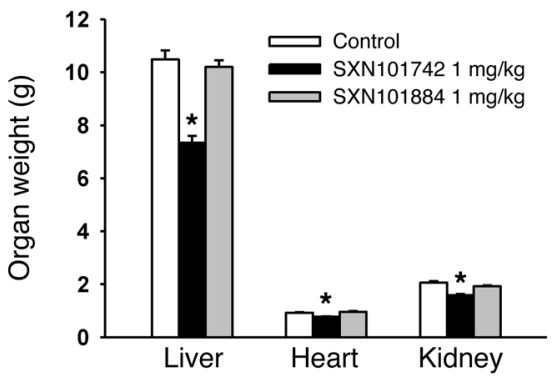

B

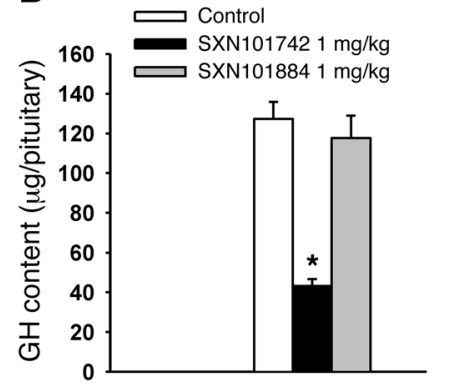

E

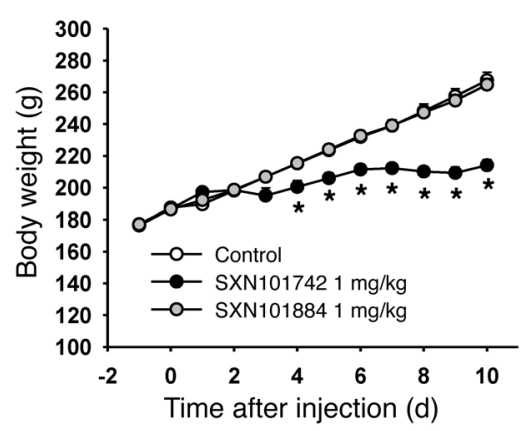

H

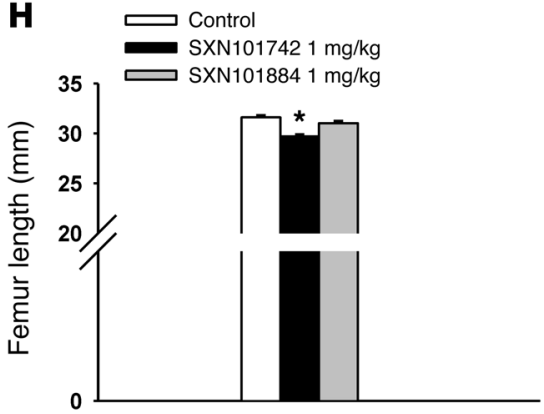

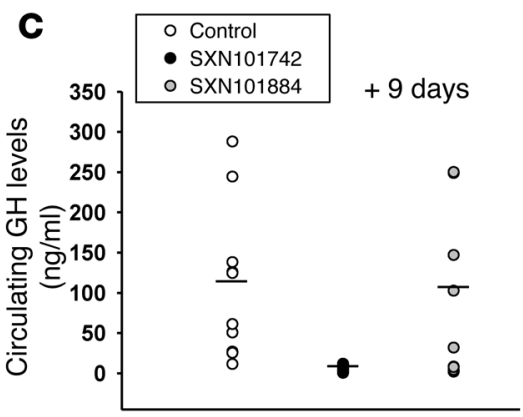

F

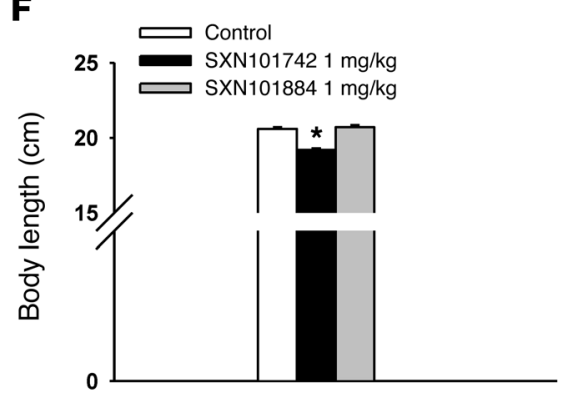

I

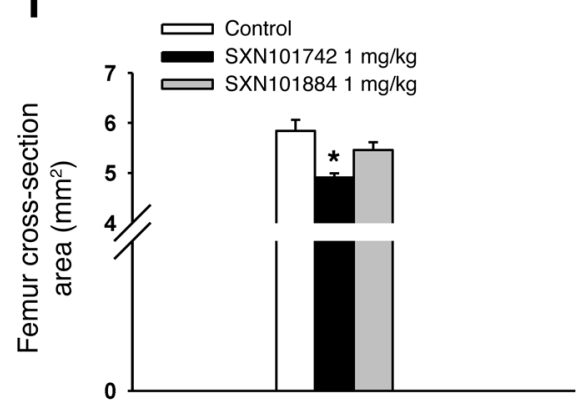

Figure 7

SXN101884 (endopeptidase-inactivated TSI) exhibits no inhibitory effect on the GH/IGF1 axis in juvenile rats (experiment no. 3). (A) Total weight of pituitary glands (mg). (B) GH content of pituitary glands ( $\mu \mathrm{g} /$ pituitary). (C) Plasma GH individual values (ng/ml) 9 days after treatment. (D) Time course of plasma IGF1 levels (ng/ml).(E) BW curves (G). (F) Body length (cm). (G) Weight of organs (liver, heart, kidney) (g). (H) Femur length $(\mathrm{mm})$. (I) Femur cross-section area $\left(\mathrm{mm}^{2}\right)$. For all panels, 45-day-old male rats received either a single injection of SXN101742 (black columns) or SXN101884 (gray columns), each at the dose of $1 \mathrm{mg} / \mathrm{kg}$, or vehicle (white columns) and were studied 10 days later (9 days for C). Results are expressed as mean \pm SEM. $n=10$ animals per group. ${ }^{*} P<0.05$ versus control group.

inhibited femur lengthening and endochondral and periosteal bone formation. The observed decreased cortical growth in our rats is in line with the reduced cortical thickness described in genetic models of IGF1 deficiency $(16)$ or haploinsufficiency $(60,61)$. Interestingly, recent clinical studies demonstrated that attenuated GH and IGF1 signaling, due, for example, to GH receptor deficiency (Laron syndrome), confer a protective effect against malignancies and diabetes development (62-64), both classical acromegaly comorbidities (9).

Although no visible disturbance was observed in SXN101742treated animals, additional work is required, especially in tissues expressing the GHRH receptor (including hypothalamus, renal medulla, and testes) to exclude adverse effects before this TSI can be considered safe for clinical trial. The presently described GH secretion inhibitor could, however, provide therapeutic advantages over current medical therapies. In fact, a single dose of this drug candidate exhibits a long-term duration of action, less dependent upon its elimination half-life from the circulation (relatively fast, approximately 12 hours) than upon the slow intracellular degradation of the catalytic endopeptidase LC. In fact, the life span of the active LC inside the targeted cell cytosol determines the length of exocytosis inhibition, a crucial characteristic in the clinical applications of the BoNT-derived molecules. Recovery experiments (data not shown) also showed that SXN101742 action is reversible, which suggests an opportunity for treatment modulation. Different durations of action could also be envisioned using other catalytically active serotypes or modified LC with their own susceptibility to ubiquitin-dependent proteolysis, the degradation process explaining differences in BoNT serotype persistence (65). The specific mode of action of GH secretion inhibitor is conceptually potent on all adenomas expressing GHRH receptor, including those harboring gsp mutations or somatostatin analog resistance. Other acromegaly treatments, such as GH receptor antagonists, reduce IGF1 production but have no direct action on GH hypersecretion. Moreover, they could attenuate the IGF1 negative feedback mechanisms, leading to 
Table 2

PCR primers for quantitative real-time PCR

$\begin{array}{lc}\text { Gene } & \text { Forward } \\ \text { Gh1 } & \text { 5'-CTATGAGAACTGAAGGACCTGGAA-3' } \\ \text { Pomc } & \text { 5'-TCCTGCTTCAGACCTCCATAGAC-3' } \\ \text { Fsh } & \text { 5'-AAGAAGACAATGTTGGTTCCAAAGA-3' } \\ \text { Lh } & \text { 5'-AAGAAGACAATGTTGGTTCCAAAGA-3' } \\ \text { Tsh } & \text { 5'-AAGAAGACAATGTTGGTTCCAAAGA-3' } \\ \text { Prl } & \text { 5'-TTCTCACTACATCCATACCCTGTATACA-3' } \\ \text { lgf1 } & \text { 5'-CCTACAAAGTCAGCTCGTTCCA-3' } \\ \text { lgfals } & \text { 5'-TGGCTGGCACAAACTGACTT-3' } \\ \text { lgfbp3 } & \text { 5'-GCGTGCAGAGCCAGTAGATACC-3' } \\ \text { lgf2 } & \text { 5'-CCGTACTTCCGGACGACTTC-3' } \\ \text { lgfbp1 } & \text { 5'-CCATTAGCACCTACAGCAGCAT-3' } \\ \text { Rps29 } & \text { 5'-GCCAGGGTTCTCGCTCTTG-3' } \\ \text { Tubb4b } & \text { 5'-GCAGTGCGGCAACCAGAT-3' }\end{array}$

Reverse
5'-CTTGAGGATCTGCCCAATACG-3'
5'-GGATGCAAGCCAGCAGGTT-3'
5'-CCCATCACTGTGGCCTTAGTAAA-3'
5'-CCCATCACTGTGGCCTTAGTAAA-3'
5'-CCCATCACTGTGGCCTTAGTAAA-3'
5'-CCTTGGCAATAAACTCACGATCT-3'
5'-GGGCTGGGACTTCTGAGTCTT-3'
5'-CTCGCCCAAGCCACAGAA-3'
5'-TGTTGGCAGTCTTTTGTGCAA-3'
5'-CGTCCCGCGGACTGTCT-3'
5'-GGGCTCCTTCCATTTCTTGAG-3'
5'-GGCACATGTTCAGCCCGTAT-3'
5'-AGTGGGATCAATGCCATGCT-3'

Cell culture. GH3 cells stably expressing the rat GHRH receptor (GH3-rGHRH-R) (Trenzyme $\mathrm{GmbH}$ ) were maintained in continuous culture in Kaighn's modified F-12 nutrient mixture supplemented with $15 \%$ heat-inactivated horse serum, $2.5 \%$ fetal bovine serum, and $5 \mathrm{~g} / \mathrm{ml}$ puromycin (Invitrogen). Cells were passaged when reaching $70 \%-80 \%$ confluence using PBSbased cell dissociation buffer to detach cells from the flask. Harvested cells were suspended in Bambanker Cryopreservation Agent (Invitrogen) and stored in liquid nitrogen.

Receptor activation assay. GH3-rGHRH-R cells were rapidly thawed in a $37^{\circ} \mathrm{C}$ water bath, transferred into $9 \mathrm{ml}$ Kaighn's modified F-12 medium, and collected by centrifugation. Cells were resuspended in assay buffer (Ham's F12, 5 mM HEPES, 10 mM

paradoxically increased GH levels, which could potentially induce IGF1-independent deleterious effects. Therefore, combination of targeted GH secretion inhibitor and GH receptor antagonist could be a highly valuable therapeutic approach for future testing.

We have validated in vivo the use of a BoNT-derived TSI as a "Trojan horse" to enter a nonneural cell type and inhibit specific hormone secretion. Actions of the TSI bearing the catalytically active serotype $\mathrm{D}$ domain $\left(\mathrm{LH}_{\mathrm{N}} / \mathrm{D}\right)$ were dose dependent and persisted for at least 10 days following a single administration. The present study supports the action of a TSI that decreases GH secretion and that could be relevant for treatment of patients with acromegaly. Beyond this proof of concept, reengineering of BoNTs with other selected lead peptides would enable targeting of different cell types for developing treatments for a variety of excessive hormonal secretion disorders.

\section{Methods}

Construction, synthesis, and purification of the TSI (SXN101742 and SXN101884). The GHRH-LH $/$ D (SXN101742) protein sequence was designed using the $\mathrm{LC}$ and $\mathrm{H}_{\mathrm{N}}$ domains of BoNT/D (NCBI Protein Database P19321), a GHRH ligand domain, a lead sequence spacer, a Factor Xa protease activation site located between the $\mathrm{LC}$ and $\mathrm{H}_{\mathrm{N}}$ domain, and a histidine tag at the carboxyl terminus. The protein sequence for SXN101742 was back-translated in silico to create an E. coli codon-optimized DNA sequence. The designed gene was synthesized (Entelechon) before being cloned into a pET $26 \mathrm{~b}$ expression vector (Merck Chemicals) with a modified cloning region to only express the synthesized gene under the expression control of a T7 promoter. Two point mutations were made within the LC zinc coordination motif to create the endopeptidase-negative control (SXN101884) expression construct. Protein expression was carried out using BL21 (DE3) cells (Merck Chemicals) grown at $37^{\circ} \mathrm{C}$ before the temperature was dropped to $16^{\circ} \mathrm{C}$ during mid-log growth and transcription initiated with $1 \mathrm{mM}$ isopropyl- $\beta-\mathrm{D}$ thiogalactopyranoside (IPTG). The soluble protein was extracted from the cells by homogenization before the target protein was purified from the clarified cell lysate using immobilized metal ion affinity, hydrophobic interaction, and anion exchange chromatography (GE Healthcare). The purification process included a factor Xa protease activation step to create the active $\mathrm{LC}+\mathrm{H}_{\mathrm{N}}$ domain structure. Where necessary, an EndoTrap column (Hyglos) was used as a final polishing step to reduce excess endotoxin levels. The final protein batches had a protein purity of at least 95\% (assessed by SDS-PAGE) and an endotoxin level below $160 \mathrm{EU} / \mathrm{mg}$.
$\mathrm{MgCl}_{2}, 1 \mathrm{mM}$ IBMX [Calbiochem], 0.01\% BSA, pH 7.4) and counted using a Nucleocounter (ChemoMetec); cell concentration was adjusted to $5 \times 10^{5}$ cells $/ \mathrm{ml}$ with assay buffer. A $10-\mu \mathrm{l}$ cell suspension $(5,000$ cells per well) was incubated in white-half area 96-well microplates in triplicate with increasing concentrations of GHRH1-44 (Bachem) (final concentration 1 pM-100 nM), SXN101742, or SXN101884 (both 10 pM-1 $\mu \mathrm{M}$ ), which had been serially diluted in buffer. Basal levels of cAMP were determined by incubating cell suspension $(10 \mu \mathrm{l})$ with buffer. Microplates were sealed and incubated at $21 \pm 3^{\circ} \mathrm{C}$ for 90 minutes (with the first 60 minutes of the incubation on an orbital shaker). A cAMP standard curve was generated on each study occasion by incubating increasing concentrations of cAMP (10 $\mu \mathrm{l}, 10 \mathrm{pM}-1 \mu \mathrm{M}$ final concentration) serially diluted in assay buffer, in triplicate, in half-area 96-well microplates containing $10 \mu \mathrm{l}$ assay buffer. Following ligand incubation, detection mix $(20 \mu \mathrm{l}$, consisting of cAMP detection buffer, Lance Eu-W8044-labeled streptavidin, cAMP-biotin, and Alexa Fluor 647-anti-cAMP antibody [Abcam]) was added to each well. LANCE cAMP assay kits were purchased from PerkinElmer, chemicals and reagents from Sigma-Aldrich, and all consumables from Fisher Scientific (Loughborough). Plates were incubated at room temperature for 24 hours, and the fluorescence emitted at $665 \mathrm{~nm}$ following excitation at $320 \mathrm{~nm}$ was measured using an EnVision Microplate Reader (PerkinElmer). Raw data obtained in cAMP assays was converted to cAMP equivalents by interpolation to a cAMP standard curve fitted to a modification of the following Hill equation: $Y=$ bottom $+\left((\right.$ top - bottom $\left.) /\left(1+10^{(\mathrm{pIC} 50-X) n \mathrm{H})}\right)\right)$, where $Y$ is the RFU, $X$ is the log molar concentration, $\mathrm{PIC}_{50}$ is the negative log of the mid-point location of the curve and $n_{\mathrm{H}}$ is the Hill slope. After conversion to cAMP equivalents $(Y)$, data were fitted to modified Hill equation to obtain estimates of $\mathrm{E}_{\max }$ (top - bottom), potency $\left(\mathrm{pEC}_{50}\right.$ ), and Hill slope.

VAMP cleavage. GH3-rGHRH-R cells were cultured in Kaighn's modified F-12 nutrient mixture supplemented with $15 \%$ heat-inactivated horse serum, $2.5 \%$ fetal bovine serum, $5 \mu \mathrm{M}$ hydrocortisone, and $5 \mu \mathrm{g} / \mathrm{ml}$ puromycin (Invitrogen). Cells were plated at 100,000 cells per well onto Matrigel-coated 96-well flatbottomed culture plates and incubated for 72 hours at $37^{\circ} \mathrm{C}, 5 \% \mathrm{CO}_{2}$, before treatment with SXN101742 or SXN101884. Cells were incubated for a further 72 hours with increasing concentrations of SXN101742 or SXN101884 in growth medium and lysed in $1 \times$ NuPAGE buffer supplemented with $0.1 \mathrm{M}$ DTT and $0.05 \mathrm{U} / \mathrm{ml}$ Benzonase $(100 \mu \mathrm{l}$ per well). Lysate proteins were separated by SDS-PAGE and transferred to nitrocellulose membranes. VAMP2 was detected using the specific antibody ab3347 at $0.1 \mu \mathrm{g} / \mathrm{ml}$ (Abcam) and densitometry of bands performed using GeneTools software (Synoptics Ltd.). A load control antibody to translationally controlled tumor protein (TCTP), ab37506, used at 
$0.3 \mu \mathrm{g} / \mathrm{ml}$ (Abcam), was included to ensure consistent loading of lysate proteins across the gels. Western blotting reagents were all purchased from Invitrogen. Percentage of VAMP2 depletion was calculated in relation to band intensities of untreated lysates. The potency with which SXN proteins produced VAMP cleavage ( $\mathrm{pEC}_{50}$ ) and maximal VAMP cleavage (top - bottom) was determined by fitting to the modified Hill equation previously described.

Animal protocols. Male Sprague Dawley OFA rats (Charles River Laboratories) were housed individually in an environmentally controlled room at the School of Medicine animal facilities (Medical Center University, University of Geneva) in standard conditions (12-hour light/12-hour dark cycle) with free access to food and water. At 45 days of life (day 0), rats were injected i.v. in the tail with vehicle or SXN101742 at the dose of $1 \mathrm{mg} / \mathrm{kg}$ (experiment no. 1), at the incremental doses of $0.1,0.3$, and $1 \mathrm{mg} / \mathrm{kg}$ (experiment no. 2, doseresponse study), or at the dose of $1 \mathrm{mg} / \mathrm{kg}$ in comparison with SXN101884, a negative control consisting of an endopeptidase-inactivated TSI (experiment no. 3). Food intake and BW were monitored daily, and blood samples were collected between 10 and 11 am on day 0 (before the injection) and on days 3, 6, and 9 after the injection in unfasted state. On day 10 , rats were anesthetized with isoflurane (Forene; Abbott Laboratories) and measured (nose-to-anus length) before sacrifice by decapitation. Pituitaries and other organs were weighed before being fixed in paraformaldehyde or frozen in liquid nitrogen and stored at $-80^{\circ} \mathrm{C}$ until later analyses.

Histology. Pituitary glands were fixed in paraformaldehyde solution at $4 \%$ for 2 hours before being dehydrated and embedded in paraffin. Fivemicrometer sections were stained with $\mathrm{H} \& \mathrm{E}$ using classical procedure. For the immunohistochemical staining, $5-\mu \mathrm{m}$ sections were deparaffinized with Neoclear (Merck) and rehydrated through graded alcohols before an antigenblocking period of 30 minutes with $1 \%$ BSA in PBS. The sections were then incubated overnight at $4{ }^{\circ} \mathrm{C}$ with primary antibodies. Anti-rat $\mathrm{GH}$ antibody was obtained from Dr. A.F. Parlow (National Hormone and Peptide Program, Torrance, California, USA). Slides were then washed with PBS before a 2-hour incubation with a secondary Alexa Fluor 555-conjugated IgG fluorescent antibody (Invitrogen). The sections were finally coverslipped with the mounting liquid Vectashield HardSet from Vector Laboratories. Digital images were obtained using an upright microscope with camera AxioCam MRc5 controlled by AxioVision AC software (Carl Zeiss MicroImaging GmbH).

Hormone measurements. Blood was collected in heparin-coated tubes by tail puncture before treatment and 3, 6, and 9 days after SXN101742 administration. Plasma samples were then collected after centrifugation (10 minutes, $2,000 \mathrm{~g}, 4^{\circ} \mathrm{C}$ ) and stored at $-20^{\circ} \mathrm{C}$ until hormonal dosage. Rat circulating GH was measured using ELISA kit EZRMGH-45K (Millipore). Rat circulating IGF1 was measured using immunoenzymometric assay kit IEMA AC-18F1 (ImmunoDiagnostics Systems). For tissue hormonal content, pituitaries were homogenized in a tissue grinder using $1 \mathrm{ml} \mathrm{PBS}$. GH protein level was measured using ELISA kit EZRMGH-45K (Millipore), TSH protein level was measured using ELISA kit AKRTS-010R (Shibayagi), and PRL protein level was measured using ELISA kit PR063F-100 (Calbiotech).

Bone development analyses. Length and cross-sectional area of the midshaft femur were measured using a microcomputed tomography analysis. Trabecular bone architecture of the distal femur was analyzed using a MicroCT UCT40 (SCANCO Medical AG), and 3D morphological parameters were evaluated by distance transformation of bone volume fraction (\%), trabecu- lar thickness $(\mu \mathrm{m})$, trabecular number $\left(\mathrm{mm}^{-1}\right)$, trabecular separation $(\mathrm{mm})$, and connectivity density $\left(\mathrm{mm}^{-3}\right)$, as previously reported (66). Femoral cortical geometry located at the femoral midshaft was assessed by the same algorithm as the trabecular structure. Cortical tissue volume $\left(\mathrm{mm}^{3}\right)$, bone volume $\left(\mathrm{mm}^{3}\right)$, the marrow volume $\left(\mathrm{mm}^{3}\right)$, and the average cortical width $(\mu \mathrm{m})$ were also measured. Bone histomorphometry was performed using a Leica Corp Q Image Analysis System (Leica Microsystems GmbH) as previously described (67). MAR ( $\mu \mathrm{m} / \mathrm{d})$ was assessed by the calcein double-labeling method $(68)$ and growth-plate thickness $(\mu \mathrm{m})$ by toluidine blue staining.

RNA preparation and gene expression analysis. Total RNA from pituitary glands or liver pieces was extracted using the RNeasy Mini Kit according to the manufacturer's protocol (QIAGEN). Two micrograms total RNA were reverse transcribed using 400 units of Moloney Murine Leukemia Virus Reverse Transcriptase (Invitrogen) in the presence of $1 \mathrm{U} / \mu \mathrm{l}$ RNasin (Promega Corp.), $0.2 \mu \mathrm{g}$ of random primers (oligo[dN]6) (Promega Corp.), $2 \mathrm{mM}$ dNTP, and $20 \mu \mathrm{M}$ of DTT (Invitrogen). The expression of the cDNAs for rat Gh1, Fsh, Lh, Tsh, proopiomelanocortin (Pomc), and Prl in pituitaries and Igf1, Igfals, Igfbp3, Igf2, and Igfbp1 in liver were determined by quantitative real-time PCR using an ABI StepOne Plus Sequence Detection System (Applera Europe) and were normalized using the housekeeping genes Rps 29 or Tubb4b (tubulin). PCR products were quantified using the Master SYBR Green Mix (Applera Europe), and results are expressed in $\mathrm{AU}$ relative to the control group mean value. Primers were designed using Primer Express software (Applera Europe) and chosen when possible on both sides of an intron to avoid amplification of eventual contaminating genomic DNA. Oligos were used at $217 \mathrm{nM}$ each (Microsynth). The sequence of the primers used is provided in Table 2.

Statistics. Results are expressed as mean \pm SEM for the indicated number of observations. The unpaired 2-tailed Student's $t$ test and repeated measures ANOVA were used when appropriate for comparison between groups of rats. A $P$ value of $<0.05$ was considered statistically significant.

Study approval. All animal procedures were designed in accordance with the Swiss Federal Act on Animal Protection, approved by the Geneva University ethics committee, and authorized by the State of Geneva Veterinary Office (Geneva, Switzerland).

\section{Acknowledgments}

We thank Anthony Fort, Madelaine Lachize, and Juliette Cicchini for their excellent technical assistance. We are grateful to Keith A. Foster and John Chaddock for their valuable advice given during the course of this study based on their intensive efforts in developing this innovative therapeutic concept using BoNT-derived drugs. S. Melmed is supported by NIH grant DK CA 75979.

Received for publication February 13, 2012, and accepted in revised form June 14, 2012.

Address correspondence to: Emmanuel Somm, Division of Development and Growth, Department of Paediatrics, University of Geneva School of Medicine, 1211 Geneva 14, Switzerland. Phone: 41.22.382.45.68; Fax: 41.22.382.43.15; E-mail: emmanuel.somm@ unige.ch.
1. Simpson LL. The origin, structure, and pharmacological activity of botulinum toxin. Pharmacol Rev. 1981;33(3):155-188.

2. Montal M. Botulinum neurotoxin: a marvel of protein design. Annu Rev Biochem. 2010;79:591-617.

3. Simpson LL. The action of botulinal toxin. Rev Infect Dis. 1979;1(4):656-662.

4. Shone CC, Hambleton P, Melling J. A 50-kDa fragment from the $\mathrm{NH} 2$-terminus of the heavy subunit of Clostridium botulinum type A neurotoxin forms channels in lipid vesicles. Eur J Biochem. 1987;167(1):175-180.

5. Erbguth FJ. From poison to remedy: the chequered history of botulinum toxin. J Neural Transm. 2008; 115(4):559-565.

6. Jaspers GW, Pijpe J, Jansma J. The use of botulinum toxin type A in cosmetic facial procedures. Int J Oral Maxillofac Surg. 2011;40(2):127-133.
7. Keith F, John C. Targeted secretion inhibitorsinnovative protein therapeutics. Toxins. 2010; 2(12):2795-2815

8. Chaddock JA, et al. Inhibition of vesicular secretion in both neuronal and nonneuronal cells by a retargeted endopeptidase derivative of Clostridium botulinum neurotoxin type A. Infect Immun. 2000; 68(5):2587-2593.

9. Melmed S. Medical progress: Acromegaly. N EnglJ 
Med. 2006;355(24):2558-2573.

10. Melmed S. Acromegaly pathogenesis and treatment. J Clin Invest. 2009;119(11):3189-3202.

11. Kopchick JJ, Parkinson C, Stevens EC, Trainer PJ. Growth hormone receptor antagonists: discovery, development, and use in patients with acromegaly. Endocr Rev. 2002;23(5):623-646.

12. Sherlock M, Woods C, Sheppard MC. Medical therapy in acromegaly. Nat Rev Endocrinol. 2011; 7(5):291-300.

13. Giustina A, et al. A consensus on criteria for cure of acromegaly. J Clin Endocrinol Metab. 2010; 95(7):3141-3148

14. Giustina A, Porcelli T. Pituitary gland: Medical therapy for acromegaly: can we predict response? Nat Rev Endocrinol. 2009;5(8):425-427.

15. Jane JA Jr, et al. Endoscopic transsphenoidal surgery for acromegaly: remission using modern criteria, complications, and predictors of outcome. J Clin Endocrinol Metab. 2011;96(9):2732-2740.

16. Bikle D, et al. The skeletal structure of insulin-like growth factor I-deficient mice. J Bone Miner Res. 2001; 16(12):2320-2329

17. Cannata D, Vijayakumar A, Fierz Y, LeRoith D. The GH/IGF-1 axis in growth and development: new insights derived from animal models. Adv Pediatr. 2010;57(1):331-351.

18. LeRoith D. Clinical relevance of systemic and local IGF-I: lessons from animal models. Pediatr Endocrinol Rev. 2008;5(suppl 2):739-743.

19. Leung KC, Waters MJ, Markus I, Baumbach WR, Ho KK. Insulin and insulin-like growth factor-I acutely inhibit surface translocation of growth hormone receptors in osteoblasts: a novel mechanism of growth hormone receptor regulation. Proc Natl Acad Sci U S A. 1997;94(21):11381-11386.

20. Madsen K, Friberg U, Roos P, Eden S, Isaksson O. Growth hormone stimulates the proliferation of cultured chondrocytes from rabbit ear and rat rib growth cartilage. Nature. 1983;304(5926):545-547.

21. Ohlsson C, et al. The role of liver-derived insulin-like growth factor-I. Endocr Rev. 2009;30(5):494-535.

22. Tachas G, et al. A GH receptor antisense oligonucleotide inhibits hepatic GH receptor expression, IGF-I production and body weight gain in normal mice. J Endocrinol. 2006;189(1):147-154.

23. Ueland T. Bone metabolism in relation to alterations in systemic growth hormone. Growth Horm IGF Res. 2004;14(6):404-417.

24. Wang J, Zhou J, Cheng CM, Kopchick JJ, Bondy CA. Evidence supporting dual, IGF-I-independent and IGF-I-dependent, roles for $\mathrm{GH}$ in promoting longitudinal bone growth. J Endocrinol. 2004;180(2):247-255.

25. Bonifacino JS, Glick BS. The mechanisms of vesicle budding and fusion. Cell. 2004;116(2):153-166.

26. Foster KA. Engineered toxins: new therapeutics. Toxicon. 2009;54(5):587-592.

27. Chaddock JA, Purkiss JR, Duggan MJ, Quinn CP, Shone CC, Foster KA. A conjugate composed of nerve growth factor coupled to a non-toxic derivative of Clostridium botulinum neurotoxin type A can inhibit neurotransmitter release in vitro. Growth Factors. 2000;18(2):147-155.

28. Duggan MJ, et al. Inhibition of release of neurotransmitters from rat dorsal root ganglia by a novel conjugate of a Clostridium botulinum toxin A endopeptidase fragment and Erythrina cristagalli lectin. J Biol Chem. 2002;277(38):34846-34852.

29. Frohman LA, Downs TR, Chomczynski P. Regulation of growth hormone secretion. Front Neuroendocrinol. 1992;13(4):344-405.

30. Dieguez C, Casanueva FF. Ghrelin: a step forward in the understanding of somatotroph cell function and growth regulation. Eur J Endocrinol. 2000; 142(5):413-417.

31. Mayo KE. Molecular cloning and expression of a pituitary-specific receptor for growth hormone-releasing hormone. Mol Endocrinol. 1992;
6(10):1734-1744

32. Arndt JW, Chai Q, Christian T, Stevens RC. Structure of botulinum neurotoxin type D light chain at 1.65 A resolution: repercussions for VAMP-2 substrate specificity. Biochemistry. 2006; 45(10):3255-3262.

33. Frohman LA, Kineman RD. Growth hormonereleasing hormone and pituitary development, hyperplasia and tumorigenesis. Trends Endocrinol Metab. 2002;13(7):299-303

34. Jacobsson G, Meister B. Molecular components of the exocytotic machinery in the rat pituitary gland. Endocrinology. 1996;137(12):5344-5356.

35. Jahn R, SüdhofTC. Membrane fusion and exocytosis. Annu Rev Biochem. 1999;68:863-911.

36. Ferraro F, Eipper BA, Mains RE. Retrieval and reuse of pituitary secretory granule proteins. J Biol Chem. 2005;280(27):25424-25435.

37. Sandstedt J, Ohlsson C, Norjavaara E, Nilsson J, Tornell J. Disproportional bone growth and reduced weight gain in gonadectomized male bovine growth hormone transgenic and normal mice. Endocrinology. 1994;135(6):2574-2580.

38. Wolf E, Wanke R, Schenck E, Hermanns W, Brem G. Effects of growth hormone overproduction on grip strength of transgenic mice. Eur J Endocrinol. 1995; 133(6):735-740.

39. Yamashita S, Slanina S, Kado H, Melmed S. Autoregulation of pituitary growth hormone messenger ribonucleic acid levels in rats bearing transplantable mammosomatotrophic pituitary tumors. Endocrinology. 1986;118(3):915-918.

40. Weckbecker G, Briner U, Lewis I, Bruns C. SOM230: a new somatostatin peptidomimetic with potent inhibitory effects on the growth hormone/insulinlike growth factor-I axis in rats, primates, and dogs. Endocrinology. 2002;143(10):4123-4130.

41. Alba M, Salvatori R. A mouse with targeted ablation of the growth hormone-releasing hormone gene: a new model of isolated growth hormone deficiency. Endocrinology. 2004;145(9):4134-4143.

42. Nagel BH, Palmbach M, Petersen D, Ranke MB. Magnetic resonance images of 91 children with different causes of short stature: pituitary size reflects growth hormone secretion. Eur J Pediatr. 1997; 156(10):758-763.

43. Bertherat J, et al. Chronic growth hormone $(\mathrm{GH})$ hypersecretion induces reciprocal and reversible changes in mRNA levels from hypothalamic GHreleasing hormone and somatostatin neurons in the rat. J Clin Invest. 1993;91(4):1783-1791.

44. Pellegrini E, Bluet-Pajot MT, Mounier F, Bennett P, Kordon C, Epelbaum J. Central administration of a growth hormone $(\mathrm{GH})$ receptor mRNA antisense increases GH pulsatility and decreases hypothalamic somatostatin expression in rats. J Neurosci. 1996; 16(24):8140-8148.

45. Pellegrini E, Carmignac DF, Bluet-Pajot MT, Mounier F, Bennett P, Epelbaum J, Robinson IC. Intrahypothalamic growth hormone feedback: from dwarfism to acromegaly in the rat. Endocrinology. 1997;138(11):4543-4551.

46. Bartlett JM, Charlton HM, Robinson IC, Nieschlag E. Pubertal development and testicular function in the male growth hormone-deficient rat. J Endocrinol. 1990;126(2):193-201.

47. Thomas GB, Phelps CJ, Robinson IC. Differential regulation of hypothalamic tuberoinfundibular dopamine neurones in two dwarf rat models with contrasting changes in pituitary prolactin. J Neuroendocrinol. 1999;11(3):229-236.

48. Chandrashekar V, Bartke A, Coschigano KT, Kopchick JJ. Pituitary and testicular function in growth hormone receptor gene knockout mice. Endocrinology. 1999;140(3):1082-1088.

49. Clemmons DR. Role of insulin-like growth factor$\mathrm{I}$ in diagnosis and management of acromegaly. Endocr Pract. 2004;10(4):362-371.
50. Clemmons DR. Clinical utility of measurements of insulin-like growth factor 1. Nat Clin Pract Endocrinol Metab. 2006;2(8):436-446.

51. Sjogren $\mathrm{K}$, et al. Liver-derived insulin-like growth factor I (IGF-I) is the principal source of IGF-I in blood but is not required for postnatal body growth in mice. Proc Natl Acad Sci U S A. 1999; 96(12):7088-7092.

52. Coschigano KT, Holland AN, Riders ME, List EO, Flyvbjerg A, Kopchick JJ. Deletion, but not antagonism, of the mouse growth hormone receptor results in severely decreased body weights, insulin, and insulin-like growth factor I levels and increased life span. Endocrinology. 2003;144(9):3799-3810.

53. Trainer PJ, et al. Treatment of acromegaly with the growth hormone-receptor antagonist pegvisomant. NEngl J Med. 2000;342(16):1171-1177.

54. Woods KA, Camacho-Hubner C, Savage MO, Clark AJ. Intrauterine growth retardation and postnatal growth failure associated with deletion of the insulin-like growth factor I gene. $N$ Engl J Med. 1996; 335(18):1363-1367.

55. Vaccarino FJ, Bloom FE, Rivier J, Vale W, Koob GF. Stimulation of food intake in rats by centrally administered hypothalamic growth hormonereleasing factor. Nature. 1985;314(6007):167-168.

56. Behringer RR, Lewin TM, Quaife CJ, Palmiter RD, Brinster RL, D'Ercole AJ. Expression of insulin-like growth factor I stimulates normal somatic growth in growth hormone-deficient transgenic mice. Endocrinology. 1990;127(3):1033-1040.

57. Shea BT, Hammer RE, Brinster RL. Growth allometry of the organs in giant transgenic mice. Endocrinology. 1987;121(6):1924-1930.

58. Guler HP, Zapf J, Scheiwiller E, Froesch ER. Recombinant human insulin-like growth factor I stimulates growth and has distinct effects on organ size in hypophysectomized rats. Proc Natl Acad Sci U S A. 1988;85(13):4889-4893.

59. Barnard R, Haynes KM, Werther GA, Waters MJ. The ontogeny of growth hormone receptors in the rabbit tibia. Endocrinology. 1988;122(6):2562-2569.

60. He J, Rosen CJ, Adams DJ, Kream BE. Postnatal growth and bone mass in mice with IGF-I haploinsufficiency. Bone. 2006;38(6):826-835.

61. Mohan S, Baylink DJ. Impaired skeletal growth in mice with haploinsufficiency of IGF-I: genetic evidence that differences in IGF-I expression could contribute to peak bone mineral density differences. J Endocrinol. 2005;185(3):415-420.

62. Guevara-Aguirre J, et al. Growth hormone receptor deficiency is associated with a major reduction in pro-aging signaling, cancer, and diabetes in humans. Sci Transl Med. 2011;3(70):70ra13.

63. Leslie M. Genetics and disease. Growth defect blocks cancer and diabetes. Science. 2011; 331(6019):837.

64. Steuerman R, Shevah O, Laron Z. Congenital IGF1 deficiency tends to confer protection against postnatal development of malignancies. EurJ Endocrinol. 2011;164(4):485-489.

65 . Tsai YC, et al. Targeting botulinum neurotoxin persistence by the ubiquitin-proteasome system. Proc Natl Acad Sci U S A. 2010;107(38):16554-16559.

66. Hildebrand T, Ruegsegger P. Quantification of bone microarchitecture with the structure model index. Comput Methods Biomech Biomed Engin. 1997; 1(1):15-23.

67. Bonnet N, Laroche N, Vico L, Dolleans E, Courteix $\mathrm{D}$, Benhamou CL. Assessment of trabecular bone microarchitecture by two different $x$-ray microcomputed tomographs: a comparative study of the rat distal tibia using Skyscan and Scanco devices. Med Phys. 2009;36(4):1286-1297.

68 . Bonnet $\mathrm{N}$, et al. The matricellular protein periostin is required for sost inhibition and the anabolic response to mechanical loading and physical activity. J Biol Chem. 2009;284(51):35939-35950. 